SCIENTIFIC REPORT

\title{
Intermittent exotropia increasing with near fixation: a "soft" sign of neurological disease
}

\author{
P H Phillips, K J Fray, M C Brodsky
}

Br J Ophthalmol 2005;89:1120-1122. doi: 10.1136/bjo.2004.063123

Aim: To examine the association of distance-near disparity with neurological disease in children with intermittent exotropia.

Methods: A retrospective analysis was performed of the medical records of all children with intermittent exotropia examined at the Arkansas Children's Hospital between 1989 and 2002. The study group consisted of children with intermittent exotropia who had a near deviation that exceeded the deviation at distance by at least 10 prism dioptres. The control group consisted of children with intermittent exotropia who had a distance deviation greater than or equal to the deviation at near. The main outcome measure was the prevalence of neurological abnormalities in the study and control groups.

Results: Among the 29 patients in the study group, 19 (66\%) had a history of concurrent neurological abnormalities. Associated neurological conditions included developmental delay (10 patients), attention deficit disorder (four patients), cerebral palsy (four patients), history of intracranial haemorrhage (four patients), periventricular leucomalacia (three patients), seizures (two patients), cortical visual impairment (two patients), hydrocephalus (one patient), history of anoxic brain damage (one patient), history of encephalitis (one patient), and autism (one patient). Among the 37 patients in the control group, seven (19\%) had a history of concurrent neurological abnormalities. The difference in the prevalence of neurological disease between the study group and the control group was significant $(p=0.0002)$.

Conclusion: Intermittent exotropia increasing with near fixation is associated with neurological disease in children.

C hildren with intermittent exotropia often have an exodeviation that increases with distance fixation. ${ }^{12}$ However, some children exhibit an exodeviation that increases during near fixation. It has been our impression that the latter group frequently has associated neurological or neurodevelopmental disorders. To test this hypothesis, we retrospectively reviewed the medical records of our patients with intermittent exotropia.

\section{METHODS}

Retrospective analysis of the medical records of all children with intermittent exotropia examined at the Arkansas Children's Hospital between 1989 and 2002. The study group consisted of children with intermittent exotropia whose near deviation was at least 10 prism dioptres greater than their distance deviation. The control group consisted of children with intermittent exotropia who had a distance deviation greater than or equal to the deviation at near. Children who had strabismus surgery were categorised by ocular motility measurements obtained before their strabismus surgery.
Children who had undergone strabismus surgery before examination by one of the investigators were excluded from the analysis. In addition, children who had a near deviation that was less than 10 prism dioptres greater than the distance deviation, who had an inconsistent distance/near disparity, or who were uncooperative for distance and near measurements were excluded from the analysis. None of the patients had amblyopia, ptosis, anisocoria, nystagmus, limited ductions or any other associated ocular disease. The absence of amblyopia was confirmed in preverbal children by the ability to maintain central steady fixation with each eye and among literate children, by the presence of visual acuity equal to or greater than 20/30 in each eye and equal visual acuity in both eyes.

All patients were examined by at least two investigators. Cover/uncover testing was used to diagnosis intermittent exotropia. Prism and alternate cover testing was performed with distance $(6$ metres) and near $(33 \mathrm{~cm})$ fixation targets in order to determine the magnitude of the exodeviation. Accurate fixation and accommodation were assured by having the patient identify different fixation targets as measurements were being obtained. Depending on the age and development of the patient, Snellen letters or Allen symbols were used as fixation targets. Ocular occlusion was not performed before obtaining the measurements noted above. When possible, confrontation visual field testing was performed to rule out hemianopic visual field deficits.

The charts were reviewed for the presence of associated ocular, neurological and systemic diseases. All patients and parents in the study and control groups were routinely questioned at each visit regarding the presence of neurological diseases including developmental delay, attention deficit disorder, and seizures. Most of the patients diagnosed with neurological disease were evaluated by a paediatric neurologist or a child development specialist before their ophthalmological evaluation.

\section{Statistical analysis}

The prevalence of neurological disease and the sex distribution in the study and control groups were compared with a two tailed $\chi^{2}$ test. The age distribution in each group was compared with a two sample $t$ test.

\section{RESULTS}

A total of 94 children had intermittent exotropia. Twenty eight children were excluded from the analysis. Reasons for exclusion included insufficient cooperation for accurate distance measurements (18 patients), an exodeviation at near that exceeded the deviation at distance by less than 10 prism dioptres (eight patients), strabismus surgery that was performed before evaluation by one of the investigators (one patient), and ocular motility measurements that were inconsistent (one patient).

The characteristics of the study and control groups are shown in table 1 . The study and control groups did not differ 
Table 1 Characteristics of the study and control groups

\begin{tabular}{|c|c|c|c|c|}
\hline & $\begin{array}{l}\text { Sex (no of females) } \\
\text { (mean) }\end{array}$ & $\begin{array}{l}\text { Age (years) } \\
\text { (mean (SD)) }\end{array}$ & $\begin{array}{l}\text { Distance deviation } \\
\text { (prism dioptres) } \\
\text { (mean (SD)) }\end{array}$ & $\begin{array}{l}\text { Near deviation } \\
\text { (prism dioptres) }\end{array}$ \\
\hline Study group $(n=29)$ & 13 & $\begin{array}{l}6.7(8.3) \\
\text { range 3-17 }\end{array}$ & $\begin{array}{l}19(10) \\
\text { range } 0-40\end{array}$ & $\begin{array}{l}35(11) \\
\text { range 10-55 }\end{array}$ \\
\hline $\begin{array}{l}\text { Control group } \\
(n=37)\end{array}$ & 17 & $\begin{array}{l}4.4(9.0) \\
\text { range 3-14 }\end{array}$ & $\begin{array}{l}30(11) \\
\text { range } 14-60\end{array}$ & $\begin{array}{l}13(11) \\
\text { range } 0-45\end{array}$ \\
\hline $\mathrm{p}$ Value & 0.87 & 0.24 & & \\
\hline
\end{tabular}

significantly with respect to sex and age at evaluation. The 29 patients in the study group had intermittent exotropia that increased with near fixation with a mean deviation of 19 prism dioptres at distance and 35 prism dioptres at near. Seventeen of these 29 patients had an intermittent near deviation greater than or equal to 35 prism dioptres indicating robust fusional convergence amplitudes; 19 of these 29 patients $(66 \%)$ had a history of concurrent neurological abnormalities as listed in table 2 .

The control group consisted of 37 patients with a mean exodeviation of 30 prism dioptres at distance and 13 prism dioptres at near. Seven of these 37 patients (19\%) had a history of concurrent neurological abnormalities as listed in table 2. The prevalence of neurological abnormalities was significantly higher in the patients who had an intermittent exotropia that increased with near fixation compared with the control group $(p=0.0002)$. Despite the significant difference in prevalence, the spectrum of neurological abnormalities was qualitatively similar between both groups.

\section{DISCUSSION}

We found a high prevalence of neurological disease in children with intermittent exotropia increasing at near fixation. Convergence insufficiency has been associated with several neurological disorders including head trauma, dyslexia, Parkinson's disease, congenital central hypoventilation syndrome, subdural haematoma, and stroke. ${ }^{3-14}$ The term "convergence insufficiency" has been loosely applied to this heterogeneous group of patients with exodeviations that become problematic during near fixation. In this context, apparent convergence insufficiency may arise from multiple mechanisms ranging from decreased fusional convergence amplitudes, a low accommodative convergence/accommodation ratio, accommodative insufficiency, poor convergence effort, poor accommodative effort, poor concentration, and pharmacological effects of medications. ${ }^{3-14}$ We are unable to assign a specific neurophysiological substrate to our study patients with intermittent exotropia that increases with near fixation. However, many of our study patients were able intermittently to fuse large exodeviation, demonstrating that their convergence amplitudes were greater than normal.

The magnitude of exodeviations at near is affected by accommodative and convergence effort. We encouraged accommodative and convergence effort by requiring our children to identify fixation targets as measurements were being obtained. However, we cannot exclude the possibility that reduced accommodative or convergence effort may have contributed to the high prevalence of exodeviations that increase with near fixation in children with neurological disease.

This study should be viewed in light of its inherent limitations. Firstly, because our cohort was gleaned from a children's hospital population, our findings do not necessarily reflect the prevalence of neurological dysfunction in the general population. However, the increased prevalence of neurological disease in our children with intermittent exotropia that increases with near fixation compared with our control group of patients suggests that this association is real. Secondly, the prevalence of neurological disease was determined from a retrospective chart review. Not every patient was examined by a paediatric neurologist. However, patients and parents were routinely questioned regarding the presence of neurological disease at each visit. It is unlikely that a more detailed paediatric neurological evaluation would have disclosed clinically significant undiagnosed neurological disease in a significant number of our apparently healthy patients. Finally, we did not formally measure accommodative or convergence amplitudes in most of our patients with intermittent exotropia that increases with near fixation.

Our study confirms a high prevalence of neurological disease in children who have intermittent exotropia that increases with near fixation. However, no patient was subsequently found to have a serious treatable neurological lesion. As such, neuroimaging is not warranted, and further diagnostic evaluation can be guided by the clinical history. Although the determinants of increased near disparity in

Table 2 Neurological diseases in study and control patients

\begin{tabular}{llll}
\hline & Study group $(\mathbf{n}=\mathbf{2 9})$ & & Control group $(\mathbf{n}=\mathbf{3 7})$ \\
\cline { 2 - 2 } Neurological diseases & No of patients* & & No of patients* \\
\hline Developmental delay & 10 & 4 \\
Cerebral palsy & 4 & 1 \\
Attention deficit disorder & 4 & 0 \\
History of intracranial haemorrhage & 4 & 1 \\
Periventricular leucomalacia & 3 & 4 \\
Seizure disorder & 2 & 0 \\
Cortical visual impairment & 2 & 0 \\
History of hydrocephalus & 1 & 0 \\
History of anoxic brain damage & 1 & 1 \\
History of encephalitis & 1 & \\
Autism & 1 & \\
\hline \multirow{2}{*}{ *Most patients had more than one neurological abnormality } &
\end{tabular}


intermittent exotropia have yet to be defined, this form of strabismus appears to be a "soft" sign of neurological disease in children should prompt a search for other signs of neurological disease.

\section{ACKNOWLEDGEMENT}

Supported in part by unrestricted grant from Research to Prevent Blindness and the Pat \& Willard Walker Eye Research Center, Jones Eye Institute, University of Arkansas for Medical Sciences.

\section{Authors' affiliations}

P H Phillips, K J Fray, M C Brodsky, Department of Ophthalmology, University of Arkansas for Medical Sciences, Little Rock, AR, USA M C Brodsky, Department of Pediatrics, University of Arkansas for Medical Sciences, Little Rock, AR, USA

Correspondence to: Paul H Phillips, MD, Arkansas Children's Hospital, 800 Marshall Street, Little Rock, AR 72202, USA; phillipspaulh@uams. edu

Accepted for publication 1 March 2005

\section{REFERENCES}

1 Kushner BJ, Morton GV. Distance/near differences in intermittent exotropia Arch Ophthalmol 1998;116:478-86.
2 Kushner BJ. Exotropic deviations: a functional classification and approach to treatment. Am Orthopt J 1998;38:81-93.

3 Krohel GB, Kristan RW, Simon JW, et al. Posttraumatic convergence insufficiency. Ann Ophthalmol 1986;18:101-4.

4 Lepore FE. Disorders of ocular motility following head trauma. Arch Neurol 1995;52:924-6.

5 Cohen M, Groswasser Z, Barchadski R, et al. Convergence insufficiency in brain-injured patients. Brain Injury 1989;3:187-91.

6 Kowal L. Ophthalmic manifestations of head injury. Aust N Z J Ophthalmol 1992;20:35-40.

7 Al-Qurainy IA. Convergence insufficiency and failure of accommodation following midfacial trauma. Br J Oral Maxillofac Surg 1995:32:71-5.

8 Latvala M-L, Korhonen TT, Penttinen M, et al. Ophthalmic findings in dyslexic school children. Br J Ophthalmol 1994;78:339-43.

9 Racette BA, Gokden M, Tychsen L, et al. Convergence insufficiency in idiopathic Parkinson's disease responsive to levodopa. Strabismus 1999;7:169-74.

10 Repka MX, Claro MC, Loupe DN, et al. Ocular motility in Parkinson's disease. J Pediatr Ophthalmol Strabismus 1996;33:144-7.

11 Goldberg DS, Ludwig IH. Congenital central hypoventilation syndrome: Ocular findings in 37 children. J Pediatr Ophthalmol Strabismus 1996;33:175-80

12 Spierer A, Huna R, Rechtman C, et al. Convergence insufficiency secondary to subdural hematoma. Am J Ophthalmol 1995;120:258-60.

13 Ohtsuka K, Maekawa H, Takeda M, et al. Accommodation and convergence insufficiency with left middle cerebral artery occlusion. Am J Ophthalmol 1988; 106:60-4.

14 Stavis $M$, Murray $M$, Jenkins $P$, et al. Objective improvement from base-in prisms for reading discomfort associated with mini-convergence insufficiency type exophoria in school children. Binoc Vis Strabismus $Q$ 2002; 17:135-42. 


\section{PostScript}

\section{LETTERS}

\section{Ultrahigh resolution optical coherence tomography of birdshot retinochoroidopathy}

Birdshot retinochoroidopathy is a rare inflammatory eye disease with typical clinical presentation and strong association with the HLA-A29 allele. Characteristic appearances on fluorescein angiogram (FA), indocyanine green (ICG) angiography, and electroretinogram (ERG) have been described. ${ }^{1}$ However, histopathology of the disease has been rare. ${ }^{2}$ The following case is an example of birdshot retinochoroidopathy imaged with ultrahigh resolution optical coherence tomography (UHR-OCT), capable of $3 \mu \mathrm{m}$ axial resolution. ${ }^{4}$ UHR-OCT is able to clearly delineate individual intraretinal layers (fig 1).

\section{Case report}

A 64 year old man presented to the New England Eye Center (NEEC) for progressive visual deterioration despite cataract surgery in the left eye 2 years earlier. The patient's major complaints were difficulty seeing at night and difficulty driving. Best corrected visual acuity (BCVA) was 20/50 right eye and 20/60 left eye. Anterior eye examination revealed mild cells and flare in both eyes, a moderate cataract in the right eye, and a posterior chamber intraocular lens in the left.

Dilated fundus examination revealed mild vitritis bilaterally. The optic discs appeared slightly pale and the retinal vasculature was narrowed. Fundus appearance was consistent with the diagnosis of birdshot retinochoroidopathy (fig 2A). FA and ICG angiography were also consistent with this diagnosis (fig 2B). Six mm radial macular OCT3 scans showed bilateral epiretinal membranes (ERM), with mild thickening in the left eye. The patient subsequently tested positive for the HLA-A29 antigen. Over the next 6 months, the patient was treated for macular oedema with intravitreal Kenalog injections in both eyes, and the macular oedema subsided.

UHR-OCT images were obtained 6 months later (fig 3), at which time BCVA remained stable. Repeat fundus examination and OCT3 imaging revealed an ERM with no macular oedema and normal retinal thickness in both eyes. UHR-OCT images additionally showed photoreceptor atrophy in several areas of both eyes. RPE degeneration was present underneath areas of photoreceptor involvement. The inner retinal layers were difficult to delineate, probably because of anatomical disorganisation of these layers.

\section{Comment}

This case represents a fairly severe case of birdshot retinochoroidopathy. In a review by Gasch et al, epiretinal membrane was the second most common complication of birdshot retinochoroidopathy next to macular oedema, ${ }^{1}$ which our patient also had on initial presentation. ERG findings have

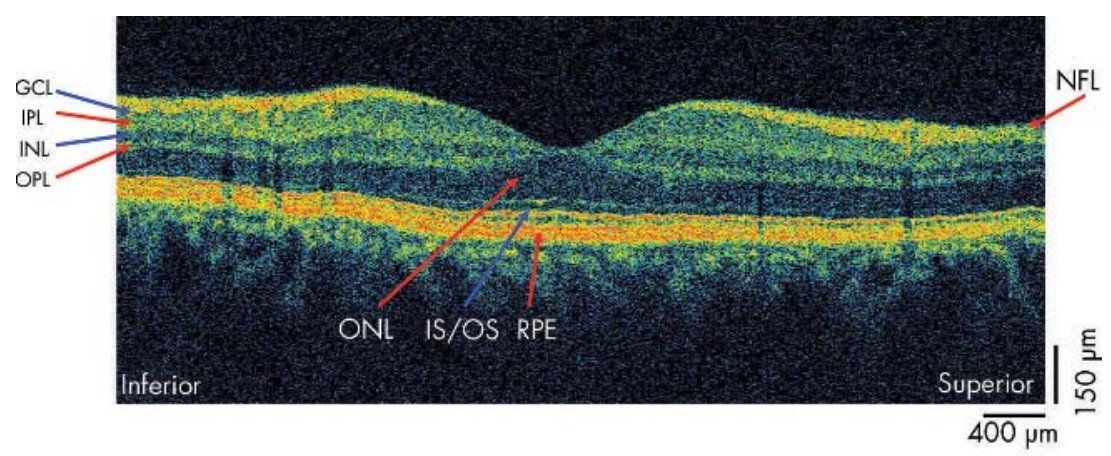

Figure 1 Ultrahigh resolution optical coherence tomography image from a normal eye. The intraretinal layers are labelled: NFL, nerve fibre layer, GCL, ganglion cell layer, IPL, inner plexiform layer, INL, inner nuclear layer, OPL, outer plexiform layer, ONL, outer nuclear layer, IS/OS, photoreceptor inner/outer segment junction, RPE, retinal pigment epithelium.
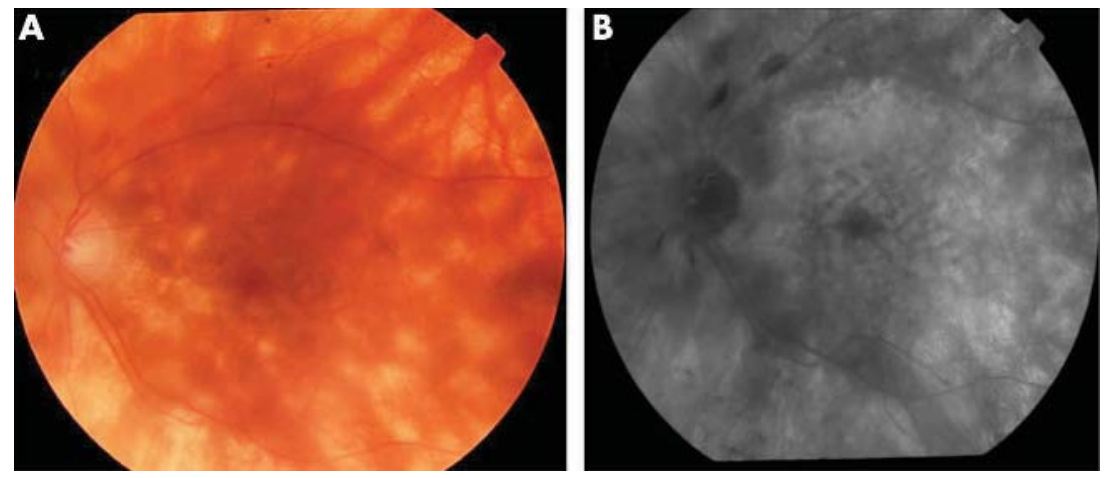

Figure 2 (A) Colour photograph of the left eye. (B) Fluorescein angiogram of the left eye, 2 minutes after injection. The image shows two small haemorrhages originating from the superior arcade, multiple hyperfluorescent spots, and central cystoid macular oedema.

shown Mueller and bipolar cell involvement early in the disease, while photoreceptors are affected later. 'The UHR-OCT images presented here show disorganisation of inner retinal layers as well as photoreceptor and RPE atrophy. Choroidal ischaemia, suggested by ICG angiography, may be the cause of RPE and photoreceptor degeneration.

We found two histolopathological reports of birdshot retinochoroidopathy. One case was a blind phthisical patient. ${ }^{2}$ The other was a more typical yet mild case, which showed lymphocytic infiltration around the choroidal and retinal vasculature with minimal retinal disturbance. ${ }^{3}$ Serial UHR-OCT imaging of patients could help in understanding and following progression of macular involvement in this disease.

A J Witkin, J S Duker New England Eye Center, Tufts-New England Medical Center, Tufts University, Boston, MA, USA

T H Ko, J G Fujimoto

Department of Electrical Engineering and Computer Science and Research Laboratory of Electronics, Massachusetts Institute of Technology, Cambridge, MA, USA
J S Schuman

UPMC Eye Center, Department of Ophthalmology, University of Pittsburgh School of Medicine, Pittsburgh, PA, USA

Correspondence to: Jay S Duker, MD Ophthalmology Department, Tufts-New England Medical Center, 750 Washington Street, Boston, MA 02111, USA; jduker@tufts-nemc.org

doi: 10.1136/bjo.2005.076570

Accepted for publication 29 July 2005

Supported in part by NIH contracts RO1-EY1 1289 16, RO1-EY13178, and P30-EY13078, NSF contract ECS-0119452, Air Force Office of Scientific Research contract F49620-98-1-0139, Medical Free Electron Laser Program contract F49620-01-1-0186 and by Carl Zeiss Meditec.

JGF and JSS receive royalties from intellectual property licensed by MIT to Carl Zeiss Meditec. JGF and JSS receive research support from Carl Zeiss Meditec

\section{References}

1 Gasch AT, Smith JA, Whitcup SM. Birdshot retinochoroidopathy. Br J Ophthalmol 1999;83:241-9. 

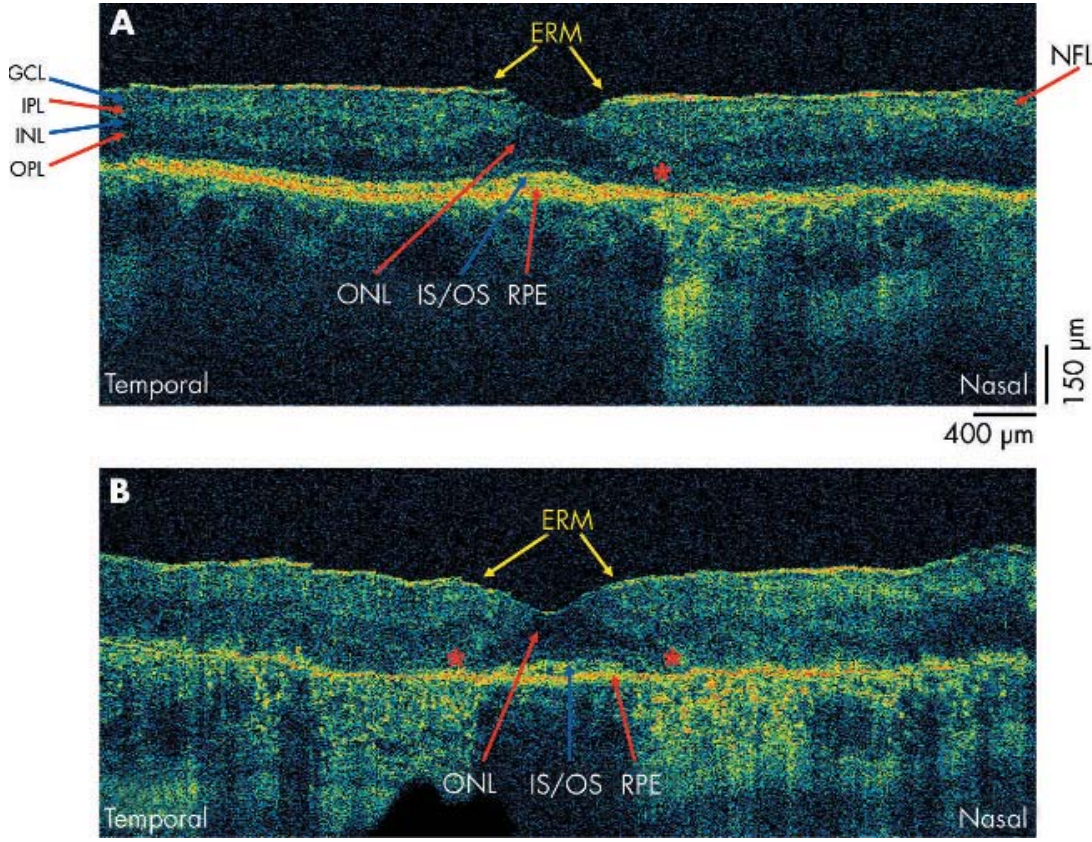

Figure 3 (A) Horizontal ultrahigh resolution OCT (UHR-OCT) image through the right macula. Notable are an epiretinal membrane (ERM) (yellow arrows), and an area of thinning of the outer nuclear layer (ONL) with underlying absence of the photoreceptor inner/outer segment junction (IS/OS) (red asterisk). Retinal pigment epithelium (RPE) disruption is also seen as an increase in choroidal signal backscattering. Other retinal layers are also labelled as in figure 1. (B) Horizontal UHR-OCT image through the left macula. ERM is present (yellow arrows). Thinning of the ONL and disruption of the photoreceptor IS/OS junction is present outside of the fovea (red asterisks). RPE disruption is also present in these areas. The inner retinal layers are not clearly delineated.

2 Nussenblatt RB, Mittal KK, Ryan S, et al. Birdshot retinochoroidopathy associated with HLA-A29 antigen and immune responsiveness to retinal Santigen. Am J Ophthalmol 1982;94:147-58.

3 Gaudio PA, Kaye DB, Crawford JB.

Histopathology of birdshot retinochoroidopathy. Br J Ophthalmol 2002;86: 1439-41.

4 Drexler W, Morgner U, Ghanta RK, et al.

Ultrahigh-resolution ophthalmic optical coherence tomography. Nat Med $2001 ; 7: 502-7$.

\section{Unilateral necrotising}

toxoplasmic retinochoroiditis as the main clinical manifestation of a peptide transporter (TAP)

\section{deficiency}

Congenital HLA class I deficiency is a rare disease frequently resulting in chronic inflammation of the respiratory tract, and/or skin granulomas. ${ }^{12}$ The deficiency may be unnoticed for decades, so pathological outcome is relatively unpredictable. ${ }^{3}$ We here describe a 14 year old patient with a severe ocular toxoplasmosis who is HLA class I deficient, as a result of a homozygous mutation in the gene encoding one of the two subunits of the peptide transporter associated with antigen processing (TAP). We propose that such a defect should be investigated in patients with severe ocular toxoplasmosis without acquired immunodeficiency.

\section{Case report}

At the time of referral, the patient did not have any particular medical history except an exaggerated reaction to an intradermal tuberculin test 1 year earlier. His right eye displayed a strong reduction of acuity with anterior and posterior inflammatory lesions with 13.48 neutrophils $\left./ \times 10^{6} / 1\right)$, while serology showed high levels of anti-toxoplasma IgG $(543 \mathrm{IU} / \mathrm{ml})$ with an IgM index of 53.73 . Anti-toxoplasma therapy was attempted by administration of sulfadiazine, pyrimethamine, and folinic acid for 2 days, followed by prednisone. Despite this treatment, the ocular inflammation worsened and led to loss of vision and ocular divergence. A clinical examination revealed posterior synechiae and aggravation of the vitritis and B echography showed retinal detachment (fig 1A).

Surgery was performed, which comprised pars plana vitrectomy after phacoemulsification, with ablation of the incompletely detached posterior hyaloid. The retina was reattached with silicone oil. The inferior retina appeared necrotic with a focus of inflammatory chorioretinitis in the macular area. Twelve months after surgery, the eye was no longer painful but vision was limited to perception of hand movements with ocular divergence (fig 1B). A fundus of the right eye revealed retraction of the inferior retina and extended gliosis of the macula (fig lC).

The severity of the clinical manifestations prompted an evaluation of the patient's immunocompetence, which appear to be normal, except that the amount of HLA class I molecules expressed on the plasma membrane of the lymphocytes was reduced 20fold (figs 2 and 3). The parents were unrelated, but shared an identical HLA haplotype, so the patient and his brother were HLA homozygous (HLA-A*24; $\mathrm{B}^{*} 14$; $\mathrm{CW}^{*} 08$; $\mathrm{DRBI}^{*} 13$; $\left.\mathrm{DQBI}^{*} 06\right)$. TAP genes, located in the HLA genetic region, were characterised, and a stop mutation in the TAPl was identified at codon 522 (sequence AAS55412.1 in GenBank), because of a C to T substitution.

The patient did not display pulmonary involvement, contrary to his elder brother who displayed a bronchial obstruction unresponsive to inhaled bronchodilators, a bacterial colonisation of the lower airways associated to asthma-like symptoms, but no bronchiectasies.

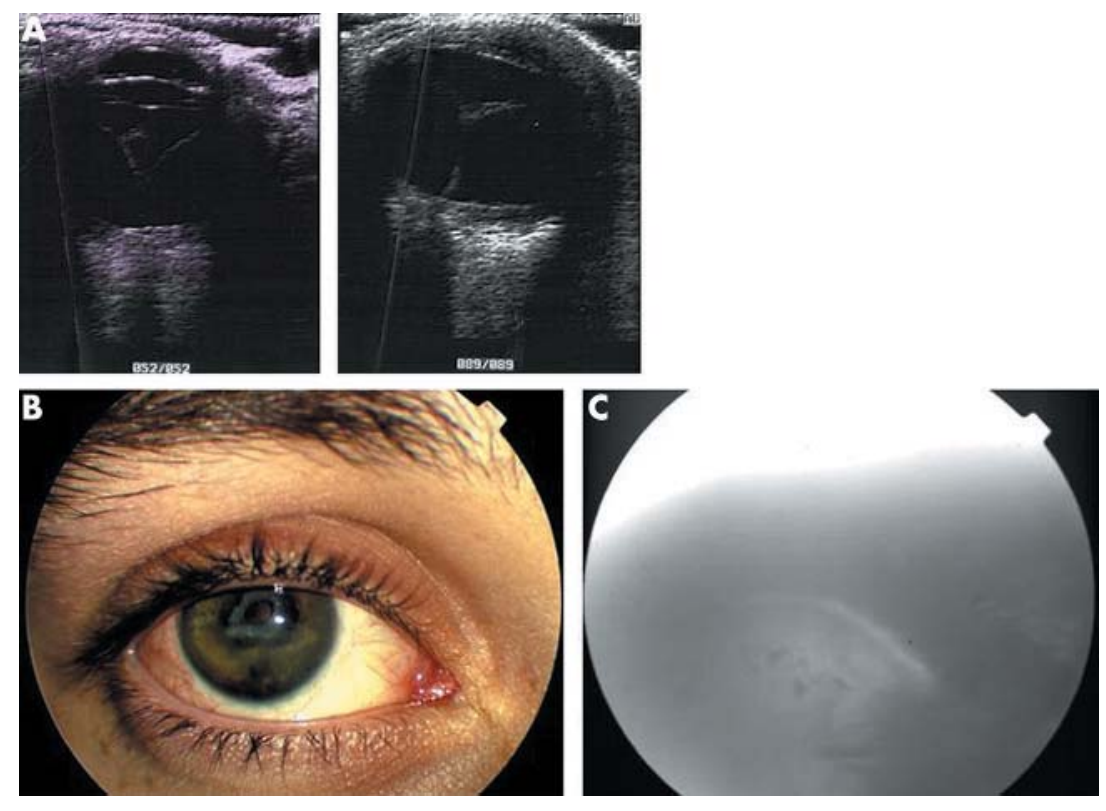

Figure 1 Analysis of lesions before and after surgery. (A) B echography before operation demonstrates total retinal detachment wit a grade $D$ vitreoretinal proliferation. (B) 12 months after surgery, circumferential synechiae are noted with capsule opacification and corneal opacities. (C) Posterior pole is not easily recognisable. Nevertheless, a white scar is distinguishable. 


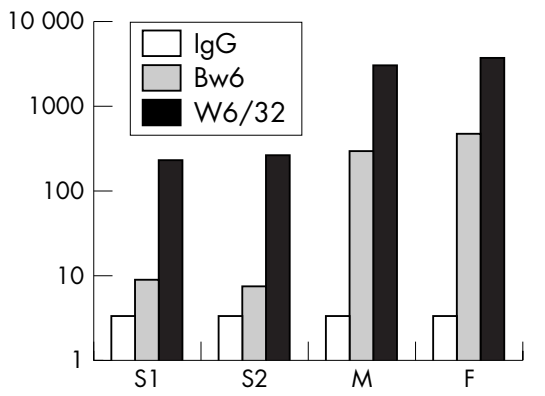

Figure 2 HLA class I deficiency of the patient and his brother. Expression of HLA class I molecules on the plasma membrane of lymphocytes. Peripheral blood mononuclear cells were isolated from the patient and his brother (S1, S2) and their parents $(M, F)$ and stained with the mAb W6/32 (pan-anti-HLA class I), or 126.39 (anti-HLA-Bw6), or a control $\operatorname{lgGl} \mathrm{mAb}$. Mean fluorescence intensities of the staining were quantified in the gated lymphocyte subpopulations.

\section{Comment}

The presence of anti-toxoplasma IgM suggests that the infection was recent and is compatible with a primary ocular infection. The particular titre of anti-toxoplasma IgG suggests that these antibodies might have had a role in the immunological defence, as has been observed for viral infections. ${ }^{4}$

Remarkably, during the pathology, more than $40 \%$ of the T cells of the patient were $\gamma \delta$, which can be explained by the infection, known to induce the expansion of this T cell subset. $^{56}$ After recovery, this number decreased twofold.

These observations suggest that TAP deficiency should now be considered as a potential cause of unexplained exacerbated pathology in response to intracellular parasites, notably $T$ gondii. In our patient, special follow up including prophylactic antibiotherapy is required, in order to avoid infection of the other eye.

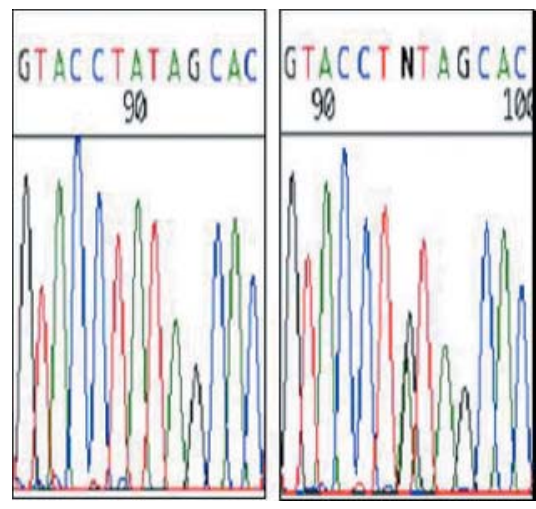

Figure 3 HLA class I deficiency of the patient and his brother. Identification of a mutation in the TAP1 gene. Genomic DNA from S1 and F was amplified using the polymerase chain reaction technique and the amplified fragments were sequenced. The sequence was read on the reverse complementary non-coding strand and showed the presence of an $A$ in the homozygous mutated genome, at the position where the superposition of an $A$ and $a G$, depicted as an $\mathrm{N}$ on the electropherogram, was observed in the hemizygous genome of $F$.

\section{Acknowledgements}

We thank José Sahel and Claude Bénichou for critical reading of the manuscript. This work was supported by ARMESA, INSERM, and the Etablissement Français du Sang-Alsace.

A Parissiadis, A Dormoy Laboratoire d'Histocompatibilité, EFS-Alsace, Strasbourg, France

D Fricker, D Hanau, $\mathrm{H}$ de la Salle INSERM U. 725, EFS-Alsace, Strasbourg, France

J-P Cazenave

INSERM U. 311, EFS-Alsace, Strasbourg, France

$P$ Lenoble

Service d'Ophtalmologie, Centre Hospitalier de Mulhouse, Mulhouse, France

L Donato

Pneumologie Pédiatrique, Hôpital Universitaire de Strasbourg, Strasbourg, France

Correspondence to: Henri de la Salle, PhD, INSERM U.725, EFS-Alsace, 10, rue Spielmann, 67065 Strasbourg Cedex, France; henri.delasalle@efs-alsace.fr

doi: 10.1136/bjo.2005.078097

Accepted for publication 1 August 2005

\section{References}

1 Gadola SD, Moins-Teisserenc HT, Trowsdale J, et al. TAP deficiency syndrome. Clin Exp Immunol 2000;121:173-8.

2 De la Salle H, Donato L, Hanau D, et al. Peptide Transporter Defects in HLA Class I Deficiency. In: Ochs HD, Smith CIE, Puck JM, eds. Primary immunodeficiency diseases. 2nd ed. New York: Oxford University Press, 2005.

3 De la Salle H, Saulquin X, Mansour I, et al. Asymptomatic deficiency in the peptide transporter associated to antigen processing (TAP). Clin Exp Immunol 2002; 128:525-31.

4 Donato L, de la Salle H, Hanau D, et al. Association of HLA class I antigen deficiency related to a TAP2 gene mutation with familia bronchiectasis. J Pediatr 1995; 127:895-900.

5 De Paoli P, Basaglia G, Gennari D, et al. Phenotypic profile and functional characteristics of human gamma and delta T cells during acute toxoplasmosis. J Clin Microbiol 1992;30:729-31.

6 Scalise F, Gerli R, Castellucci G, et al. Lymphocytes bearing the gamma delta T-cell receptor in acute toxoplasmosis. Immunology 1992;76:668-70.

\section{Scleral contact lenses are not optically inferior to corneal lenses}

In the 1950s, chronic corneal hypoxia and its attendant complications were associated with scleral contact lenses (ScCLs) compared to corneal contact lenses (CCLs). ${ }^{1}$ Changes in mechanical design to improve transfer of oxygenated tears between the corneal-tear film interface were partially successful, but accompanied by increased complexity of lens fitting and design. ${ }^{2}$ These included fenestrations, slots, truncations, and channels. Apart from being time consuming and technically difficult to manufacture, these modifications were almost invariably associated with trapping of air bubbles behind the SCCL, resulting in reduced vision and localised corneal desiccation. Without a sealed tear film, the ScCL rested progressively more on the corneal apex and limbus-that is, settling back, which caused corneal erosions, scarring, and hypoxia.
The advent of fluorocarbon silicone/acrylate co-polymer ScCLs resulted in greater utility because of high gas permeability. ${ }^{3}$ One major criticism of ScCLs has been the suboptimal visual acuity achieved when compared to CCLs. ${ }^{3}$ In this study we compared the best corrected visual acuity (BCVA) in patients with RGP ScCLs who failed a trial of CCLs.

\section{Method and results}

The case notes of 15 patients prescribed ScCLs were reviewed over an 18 month period. The reasons for discontinuing CCL use included discomfort, excessive mobility, poor fit, short wearing times, and subjective lens intolerance. There were 18 eyes in 15 patients whose average age was 37 years ( 18 $80)$. There were eight males and seven females.

The BCVA varied according to the preexisting pathology. These were post-penetrating keratoplasty (seven); keratoconus (six), and herpetic scarring (two). Mean astigmatism was 9.7D (3.5-18D). CCL average BCVA was 6/18, but with ScCLs was 6/9, of which eight $(44 \%)$ achieved $6 / 5, p=0.1 ; \chi^{2}$ test.

The greatest improvement occurred in the keratoconus group (BCVA 6/18 with CCLs; to 6/9-6/5 with ScCLs); followed by the keratoplasty group (with ScCL 6/9 in five cases and $6 / 18$ in two cases from pre-existing corneal scarring). In all cases the scleral lenses were well tolerated. No complications were noted.

\section{Comment}

The relatively close apposition of the cornea to a CCL provides a stable refractive interface. In a normal cornea, the centre is assumed to be spherical and regular so that a singly curved CCL can be made based on keratometry readings. In corneas with highly abnormal topography such as high astigmatism, severe flattening, apical protrusion, thinning, and scarring, the nature of the refractive interface between the cornea, precorneal tear film, and contact lens is altered because the above assumptions no longer hold true.

ScCLs vault the cornea, which eliminates the need for close alignment to the cornea. This compensates for very abnormal corneas giving good BCVA that can be difficult to achieve with CCLs. ${ }^{4}$ As the power of CCLs increases, positional stability and accuracy of fit decreases. High power CCLs tend to be bulkier, thicker, and with a larger diameter that alters the centre of gravity. These CCLs tend to sag or droop with axis mislocation so vision is through the peripheral lens and not the optic zone. Induced prismatic effects cause reduced vision, lens intolerance, and discomfort. This is exacerbated by edge sensation from high edge lift. Lens instability with excessive frictional mobility on the cornea also increases the potential for erosions, scarring, and intolerance. ScCLs retain positional stability and tend not to be associated with the aforementioned problems.

Based on the findings of this study, we think the use of ScCLs should not be prejudiced because of the perception that they are optically inferior to CCLs. The optical and therapeutic benefit of ScCLs should not be underestimated. They can have an important role in management of patients where surgery is undesirable or high risk.

A Salam, B Melia Hull and East Yorkshire Eye Hospital, Fountain Street, Anlaby Road, Hull HU3 2JZ, UK 
A J Singh

Department of Ophthalmology, Leeds General Infirmary, Clarendon Wing, Belmont Grove, Leeds,

Correspondence to: A J Singh, Department of Ophthalmology, Leeds General Infirmary, Clarendon Wing, Belmont Grove, Leeds LS2 9NS, UK mraniljsingh@yahoo.co.uk

doi: 10.1136/bjo.2005.074377

Accepted for publication 24 July 2005

\section{References}

1 Tan DT, Pullum KW, Buckley RJ. Medical applications of scleral contact lenses: 1. A retrospective analysis of 343 cases. Cornea 1995; 14:121-9.

2 Tan DT, Pullum KW, Buckley RJ. Medical applications of scleral contact lenses: 2. Gaspermeable scleral contact lenses. Cornea 1995; 14:130-7.

3 Pullum KW, Buckley RJ. A study of 530 patients referred for rigid gas permeable scleral contact lens assessment. Cornea 1997:16:612-22.

4 Schein OD, Rosenthal P, Ducharme C. A gaspermeable scleral contact lens for visual rehabilitation. Am J Ophthalmol 1990 15;109:318-22.

\section{Optometric referrals: towards a two way flow of information?}

ommunity optometrists in the United Kingdom carry out 17.2 million primary eyecare examinations per annum, ${ }^{1}$ which result in at least 0.5 million referrals to the hospital eye service. ${ }^{23}$ Optometrists only infrequently receive a reply to these referrals, ${ }^{45}$ possibly because $69 \%$ are handwritten on GOS18 forms, ${ }^{6}$ which can lack legibility ${ }^{6}$ and details. ${ }^{5}$ Most optometrist initiated referrals take place via general practitioners (GPs), who are increasingly likely to forward the optometrist's letter. ${ }^{6}$ We improved our referrals and audited the replies.

\section{Methods}

The Institute of Optometry set minimum criteria for referrals in 2004 by typing letters on headed notepaper, including the practitioner's name, enclosing a second copy for the GP to forward to the ophthalmologist, and including text which explicitly requested a reply.

In February-April 2005 we audited referrals from 2004. Handwritten emergency referrals, which make up less than $1 \%$ of referrals, were not included.

\section{Results}

There were 181 referrals following 7164 eye examinations, $51 \%$ were female, and the reasons for referral are given in figure 1 . The provisional diagnoses for the "other" category include a wide range of conditions, all with a prevalence of less than $3 \%$.

A reply was requested in $95 \%$ of letters, but was received for only 23 (13\%). There was no relation between the likelihood of reply and the reason for referral $(\mathrm{p}=0.37)$.

\section{Comment}

The institute's referral rate $(2.5 \%)$ is lower than previously reported for optometrists. ${ }^{2}$ This might reflect better facilities for monitoring (for example, ocular hypertension) or managing (for example, dry eye) conditions and an ethos that encourages management when appropriate.

Although our results are only for one centre it is disappointing that, despite taking steps to

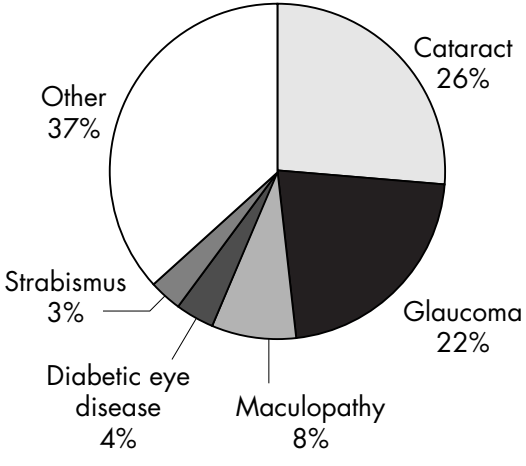

Figure 1 Reasons for referral.

encourage a reply, this is still rarely forthcoming. The proportion of referrals that receive replies is so low (13\%) that we think it unlikely to be attributable to patients failing to consult the GP or ophthalmologist after referral. For the few ophthalmologists who do reply this is not an onerous task: they instruct their secretary to copy the reply to the GP to the optometrist. The NHS code of practice on confidentiality notes that explicit consent is not usually required for information disclosures that support the delivery of the patient's care. ${ }^{7}$ Even if it is thought necessary to obtain consent, there is no good reason why the ophthalmologist should not obtain this. ${ }^{4}$ The issue of consent does not seem to be the main reason for lack of replies: a study found that ophthalmologists actually replied to a higher proportion of referrals when the optometrists had not obtained consent than when they had. ${ }^{4}$

Replying to referrals helps optometrists provide continuing patient care and avoids possible errors from the optometrist relying on the patient's recollection of the ophthalmologist's findings. Feedback also contributes to optometrists' professional development and helps to ensure that inappropriate referrals are minimised in the future. ${ }^{8}$

Now that direct referral from primary care optometrists to secondary care ophthalmology units is becoming more commonplace, ${ }^{9}$ we hope that a two way flow of information will become the norm.

B J W Evans, D E Harle, B Cocco Institute of Optometry, 56-62 Newington Causeway, London SE1 6DS, UK

Correspondence to: Professor Bruce Evans, Institute of Optometry, 56-62 Newington Causeway, London SE1 6DS, UK; bruce.evans@virgin.net

doi: 10.1136/bjo.2005.075531

Accepted for publication 24 July 2005

\section{References}

1 Department of Health. Sight tests volume and workforce survey 2003-2004. www.dh.gov.uk/ assetRoot/04/08/65/64/04086564.pdf 2004, accessed 11 April 2005.

2 Hobley AJ, Woodward EG, Port MJ. Retrospective study of optometric referrals. Ophthalmic Physiol Opt 1992;12:395-9.

3 Port MJ. Referrals and notifications by optometrists within the UK: 1988 survey. Ophthalmic Physiol Opt 1989;9:31-5.

4 Whittaker KW, Ikram K, Anderson DF, et al. Noncommunication between ophthalmologists and optometrists. J R Soc Med 1999:92:247-8.

5 Lash SC. Assessment of information included on the GOS 18 referral form used by optometrists. Ophthalmic Physiol Opt 2003;23:21-3.
6 Pooley JE, Frost EC. Optometrists' referrals to the hospital eye service. Ophthal Physiol Opt 1999;19:S16-S24.

7 Department of Health. Confidentiality: NHS Code of Practice. www.publications.doh.gov.uk/ipu/ confiden/protect/copv3.pdf 2003, accessed 11 April 2005.

8 Ingram DV, Culham LE. Ophthalmologists and optometrists-interesting times? Br J Ophthalmol 2001;85:769-70.

9 Department of Health. Delivering quality in primary care: General ophthalmic service practitioners. www.dh.gov.uk/assetRoot/04/10/60/33/ 04106033.pdf 2005, accessed 11 April 2005.

Retinal changes in juvenile $X$ linked retinoschisis using three dimensional optical coherence tomography

Juvenile X linked retinoschisis is a congenital $\mathrm{X}$ linked recessive retinal disorder, the characteristic funduscopic findings of which are a silver-grey retinal reflex, foveal retinoschisis, and peripheral retinoschisis. Electroretinograms (ERGs) typically record a reduced bwave amplitude with relative preservation of the a-wave amplitude. Visual acuity (VA) usually deteriorates slowly until the patient is about 20 years of age, stabilises around $0.2 \sim 0.5$, and sometimes deteriorates further because of macular degeneration. ${ }^{1-4}$

Podoleanu and associates developed a novel integration of scanning laser ophthalmoscopy (SLO) and optic coherence tomography (OCT)-three dimensional optical coherence tomography (3-D OCT). ${ }^{5}$ Using transverse scanning, typical for SLO, the instrument simultaneously produces SLO and interferometric OCT images. ${ }^{6}$ We can obtain both cross sectional scans (B-scans) as with conventional OCT and transverse scans (C-scans) using 3-D OCT. This is the first report of 3-D OCT findings in juvenile $\mathrm{X}$ linked retinoschisis

\section{Case report}

A 7 year old boy presented with VA of 0.5 and 0.6 in the right and left eyes, respectively. Funduscopy showed a silver-grey retinal reflex and cartwheel-like macular degeneration bilaterally. Peripheral retinoschisis was absent. ERGs were recorded and dark adaptation testing was performed. Single flash ERG showed decreased b-wave amplitude, which was consistent with the diagnosis. Dark adaptation revealed a decreased curve overall.

The B-scan findings of 3-D OCT (fig 1) showed the retina split into four distinct planes. Two wide hyporeflective spaces split the retina. Anteroposterior or oblique linear columns were seen across the superficial wide hyporeflective space, forming a bridge that was not found in the fovea. These columns are considered to be Muller cells by OCT and histological studies. ${ }^{38}$

There was a large cystoid space in the fovea connected to the superficial wide hyporeflective parafoveal space. A deeper wide hyporeflective space was in the parafoveal retina but disappeared in the fovea. Small cystoid spaces in the superficial parafoveal retina split the retina. Retinal cleavage involving the fovea was found in the outer plexiform layer. Superficial retinal cleavage was most likely in the nerve fibre layer or the ganglion cell layer. The deep retinal cleavage was in or just around the outer nuclear layer. C-scan findings of 3-D OCT showed the extent of the cleavage planes and the hyporeflective spaces (fig 2). Of particular note, the C-scans 


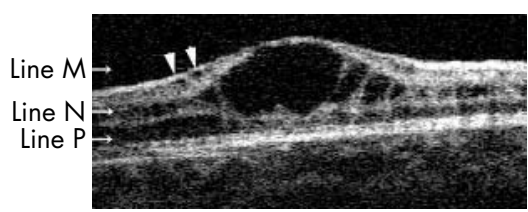

Figure 1 B-scans of 3-D OCT. Two wide hyporeflective spaces split the retina. Anteroposterior or oblique linear columns form a bridge across a superficial wide hyporeflective space. In the same layer, there is a large cystoid space in the fovea (line N). This layer is probably the outer plexiform layer.

Deeper cleavage is seen in the parafoveal area but not in the fovea (line P). This layer is probably the outer nuclear layer. Small cystoid spaces (arrowhead) are seen in the superficial parafoveal retina that split the retina (line M). This layer is probably the nerve fibre layer or the ganglion cell layer.

showed many columns in a large space (schisis). This is in contrast with the B-scans that showed the spaces between the columns to be cystic spaces. The C-scans provided a better understanding of this pathology.

\section{Comment}

Recently, conventional OCT findings of foveal schisis were reported $^{17}$ to be in the outer plexiform layer and adjacent nuclear layers. Histopathologically, foveal schisis was reported to occur in the outer plexiform layer, ${ }^{2}$ although peripheral retinoschisis was found in the nerve fibre layer and ganglion cell layer.'

3-D OCT demonstrated that schisis can occur in any retinal layers in juvenile X linked retinoschisis. We obtained cross sectional and transverse images of the retinoschisis with near histological precision that showed the details of the inner retinal structures and the extent of the schisis. 3-D OCT is useful to evaluate, non-invasively, the retinal pathology and follow patients with juvenile $\mathrm{X}$ linked retinoschisis.

Y Minami, S Ishiko, Y Takai, Y Kato, H Kagokawa, A Takamiya, T Nagaoka, R Kinouchi, A Yoshida Department of Ophthalmology, Asahikawa Medical College, Asahikawa, Japan

Correspondence to: Satoshi Ishiko, Department of Ophthalmology, Asahikawa Medical College, 2-1 Midorigaoka Higashi, Asahikawa, 078-8316, Japan; ishiko@asahikawa-med.ac.jp
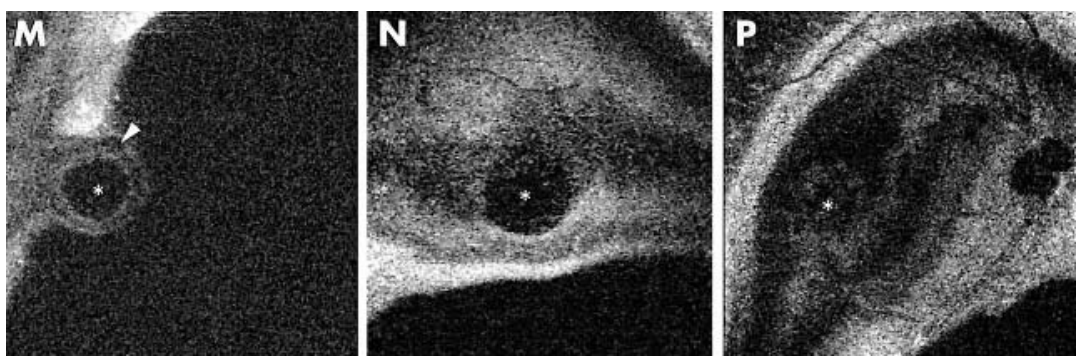

Figure 2 C-scans of 3-D OCT. C-scans $M, N$, and $P$ correspond to the same depth of the B-scans (fig 1 ) in lines $M, N$, and $P$. ${ }^{*}$ The location of the fovea. (M) A large cystic space is seen in the fovea and the retina, which includes the small cystic spaces. The small spaces found in the B-scan are confirmed in the $\mathrm{C}$-scan. (N) This space is equivalent to a superficial schisis and shows the space in the fovea and the columns around it. In B-scan images, the spaces between the columns are hypothesised to be cystic space; however, in C-scan images, these spaces are not cystic, and many columns can be seen in a large space (schisis). (P) This is equivalent to the deeper schisis and shows the hyperreflective area (no schisis) in the fovea and the large space (schisis) around the fovea. earlier he had fractured his left ankle and developed osteomyelitis from methicillin resistant Staphylococcus. He had received linezolid $600 \mathrm{mg}$ by mouth twice a day for 12 months, then once daily for 44 months. Other medications included rosiglitazone, metoprolol, rifampin, furosemide, lisinopril, amlodipine, insulin, and vitamin B complex/ folic acid for assistance with wound healing. He was a non-smoker and consumed less than one unit of alcohol per week.

Best corrected visual acuities were 20/400 in both eyes with eccentric fixation. Ishihara colour plates were $1 / 8$ right eye and 3/8 left eye. No relative afferent pupillary defect was present. Intraocular pressures were $16 \mathrm{~mm} \mathrm{Hg}$ in both eyes. 1+ nuclear sclerosis was present in both eyes. Fundus examination revealed temporal optic nerve pallor with a corresponding temporal nerve fibre layer defect more evident in the right eye (fig 1) and a normal macula in both eyes. Humphrey visual field testing (full field 120 point screen) revealed central scotomas in both eyes (fig 2). Fluorescein angiography revealed a normal macula without staining of the peripapillary region in both eyes (not shown). Optical coherence tomography (Stratus OCT, Carl Zeiss Ophthalmic Systems Inc, Humphrey Division, Dublin, CA, USA) of the fovea revealed a central foveal thickness of 205 (SD 5) $\mu \mathrm{m}$ right eye and 216 (4) $\mu \mathrm{m}$ left eye and a normal macular volume ( $7.28 \mathrm{~mm}^{3}$ right eye; $6.94 \mathrm{~mm}^{3}$ left eye). Retinal nerve fibre layer thickness analysis by OCT revealed a normal $360^{\circ}$ average measurement $(79.55 \mu \mathrm{m}$ right eye, $80.57 \mu \mathrm{m}$ left eye) with no significant change in thickness detected in the temporal quadrant (64 $\mu \mathrm{m}$ right eye and $58 \mu \mathrm{m}$ left eye). Full field scotopic and photopic electroretinography demonstrated a normal amplitude and latency in both eyes, as expected given the small central scotoma.

The patient was diagnosed with bilateral optic neuropathy; chronic use of linezolid was suspected as the cause. Linezolid was discontinued and the patient noted subjective visual improvement within several weeks. Three months later his vision improved to 20/ 40 in both eyes with resolution of the central scotomas (fig 2). There were $8 / 15$ and $13 / 15$ central fixation losses in the right and left eye respectively initially; this improved to $4 / 15$ right eye and 2/16 left eye 3 months after discontinuing therapy.

\section{Comment}

Toxic optic neuropathy has been associated with numerous compounds, including exposure to ethylene glycol, methanol, isoniazid, ethambutol, and fluoroquinolone, and deficiency of vitamin B12, folate, and thiamine. ${ }^{23}$ Linezolid was approved by the FDA, based on studies employing 28 days of administration. ${ }^{1}$ There have been five cases of optic neuropathy associated with prolonged use of linezolid $^{3-6}$ and more than 20 cases of peripheral neuropathy including one individual who developed both sequelae. ${ }^{6-9}$ In previous optic neuropathy cases the duration of treatment ranged from 5-10 months at a dose of $600 \mathrm{mg}$ once or twice per day. ${ }^{3-6}$ All cases were bilateral with initial vision decreased from $20 / 60$ to counting fingers both eyes..$^{3-6}$ Discontinuation of therapy resulted in improvement of the optic neuropathy with significant improvement in visual acuity within $1-8$ months in all patients, although 


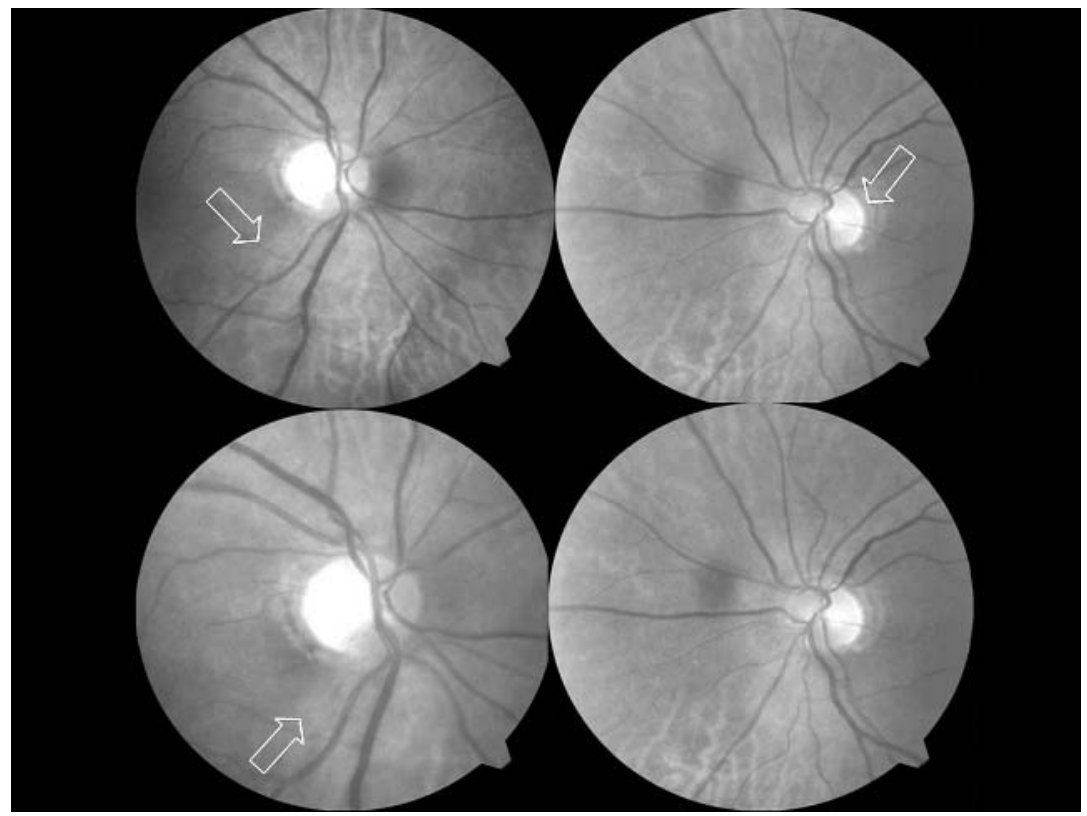

Figure 1 Top, photograph suggests subtle temporal pallor to the optic nerve in the right eye with a nerve fibre layer defect temporally (arrow, upper left); left eye appears normal (arrow, upper right) with no evident nerve fibre layer defect. Bottom, 3 months after discontinuing linezolid there is temporal pallor and nerve fibre layer defects in the right eye (lower left), again with no definite changes in the left eye (lower right).

residual deficits in central acuity or visual evoked response may persist. ${ }^{3-6}$

Oxazolidinones inhibit bacterial protein synthesis by binding to the $70 \mathrm{~S}$ ribosomal

initiation complex. $^{10}$ In nutritional optic neuropathies, paracentral scotomas develop from disruption in mitochondrial function in retinal ganglion cells, ${ }^{8}$ which are more

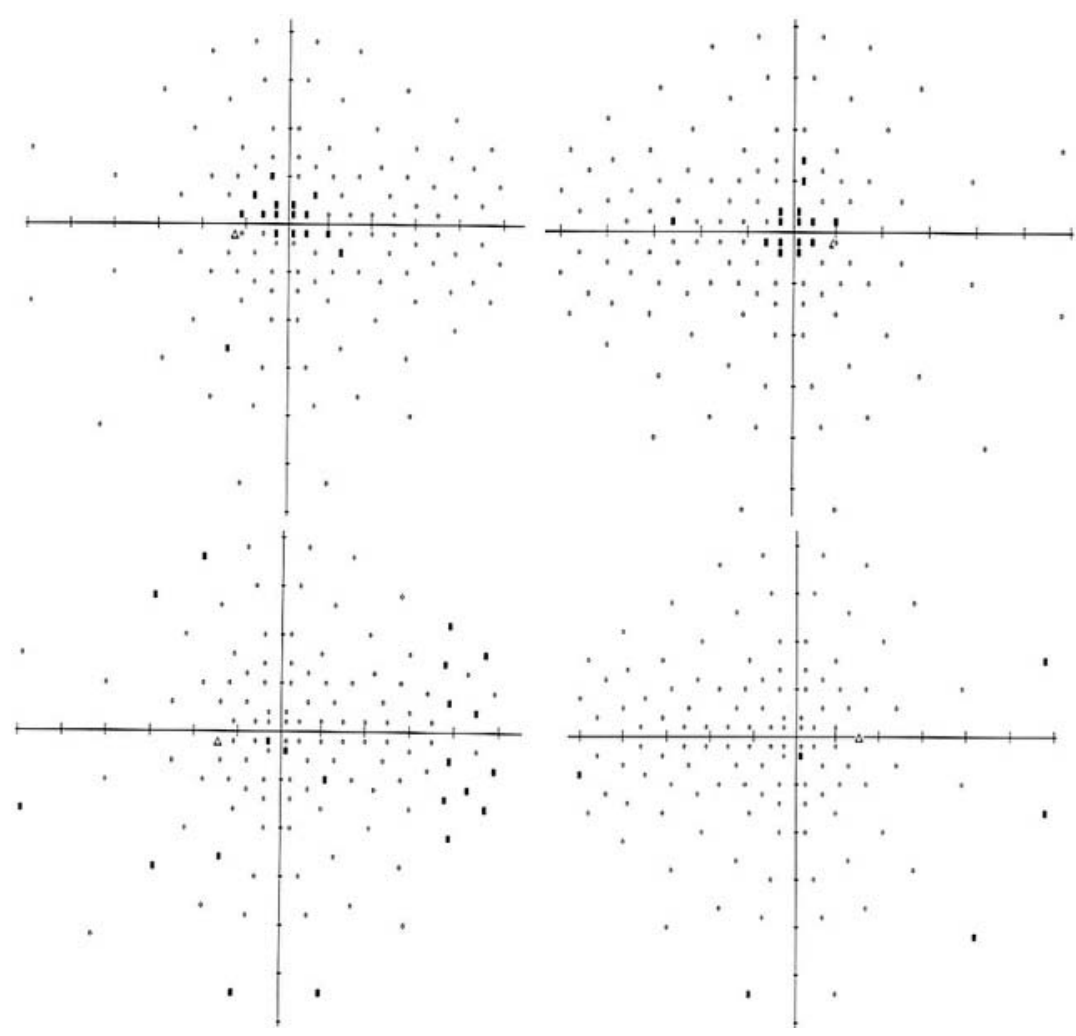

Figure 2 Humphrey full field 120. Top left and right, left eye and right eye, respectively, demonstrating central scotomas at presentation. Bottom left and right, left eye and right eye, respectively, showing improvement in the central scotomas 3 months after discontinuation of linezolid. susceptible to mitochondrial disruption. ${ }^{2}$ Mitochondrial dysfunction is the cause of Leber's hereditary optic neuropathy, chloramphenicol induced bone marrow suppression, and optic neuropathy due to ethambutol and a variety of antibiotics. ${ }^{211} 12$ It is likely that the development of linezolid associated optic neuropathy, manifest by the development of central scotomas and temporal optic nerve pathology, may be the result of a similar mechanism.

It is important for ophthalmologists to perform a complete review of systems and elicit a history of prescription and nonprescription medication use. Awareness of the potential for linezolid induced optic neuropathy is important since drug withdrawal can lead to visual recovery.

K Kulkarni, L V Del Priore

Department of Ophthalmology, Columbia University, 635 West 165th Street, New York, NY 10032, USA

K Kulkarni

University of Medicine and Dentistry of New Jersey, Robert Wood Johnson Medical School, 675 Hoes Lane, Piscataway, NJ 08854, USA

Correspondence to: Lucian V Del Priore, MD, PhD, Robert L Burch III Scholar, Department of Ophthalmology, Columbia University, 635 West 165th Street, New York, NY 10032, USA; Idelpriore@ yahoo.com

doi: 10.1136/bjo.2005.074237

Accepted for publication 1 August 2005

\section{References}

1 Birmingham MC, Rayner CR, Meagher AK, et al. Linezolid for the treatment of multidrug-resistant, gram-positive infections: experience from a compassionate-use program. Clin Infect Dis 2003;36: 159-68.

2 Carelli V, Ross-Cisneros FN, Sadun AA. Mitochondrial dysfunction as a cause of optic neuropathies. Prog Retin Eye Res 2004;23:53-89.

3 Lee E, Burger S, Shah J, et al. Linezolid-associated toxic optic neuropathy: a report of 2 cases. Clin Infect Dis 2003;37:1389-91.

4 Frippiat F, Bergiers C, Michel C, et al. Severe bilateral optic neuritis associated with prolonged linezolid therapy. J Antimicrob Chemother 2004;53:1114-15.

5 Lewis KE, Ebden P, Wooster SL, et al. Multisystem infection with Nocardia farcinicatherapy with linezolid and minocycline. J Infect 2003;46: 199-202

6 Corallo CE, Paull AE. Linezolid-induced neuropathy. Med J Aust 2002;177:332.

7 Bressler AM, Zimmer SM, Gilmore JL, et al. Peripheral neuropathy associated with prolonged use of linezolid. Lancet Infect Dis 2004; 4:528-31.

8 Rho JP, Sia IG, Crum BA, et al. Linezolid associated peripheral neuropathy. Mayo Clin Proc 2004;79:927-30.

9 Legout L, Senneville E, Gomel JJ, et al. Linezolidinduced neuropathy. Clin Infect Dis 2004;38:767-8.

10 Shinabarger DL, Marotti KR, Murray RW, et al. Mechanism of action of oxazolidinones: effects of linezolid and eperezolid on translation reactions. Antimicrob Agents Chemother 1997;41:2132-6.

11 Skinnider LF, Ghadially FN. Chloramphenicolinduced mitochondrial and ultrastructural changes in hemopoietic cells. Arch Pathol Lab Med 1976;100:601-5.

12 Bernstein WB, Trotta RF, Rector JT, et al. Mechanisms for linezolid-induced anemia and thrombocytopenia. Ann Pharmacother 2003;37:517-20. 


\section{Delayed progressive visual loss following wrapping of bilateral clinoidal aneurysms: recovery of vision and improvement in neuroimaging during corticosteroid treatment}

Reinforcement with muscle, cotton, fibrin glue, or some other material is an alternative to clipping in some intracranial aneurysms ${ }^{1}$, the surgeon must balance the need to create local inflammation (to reinforce the arterial wall) with the risk that the inflammation will spread and damage adjacent structures. Wrapping of clinoidal aneurysms, in particular, rarely may produce delayed and severe visual loss or ocular motor dysfunction..$^{2-7}$ The clinical course and potential outcome of damage to the visual pathway, ocular motor tracts, or both remains controversial, as does the optimum management when visual loss occurs. We present the case of a patient who developed severe bilateral visual loss and neuroimaging evidence of inflammation in the paraclinoid and suprasellar regions 2 months after wrapping of bilateral clinoidal aneurysms with cotton and fibrin glue, but who recovered visual function and whose neuroimaging appearance improved after treatment with systemic corticosteroids.

\section{Case report}

A 61 year old woman underwent magnetic resonance imaging (MRI) and angiography after experiencing a minor stroke. The studies revealed aneurysms of the clinoidal portion of both internal carotid arteries. Endovascular treatment was unsuccessful. Accordingly, craniotomy was performed. As neither aneurysm could be clipped, both were wrapped with cotton gauze saturated with fibrin glue. The patient did well postoperatively until 2 months after surgery, when she noted blurred vision in the right eye. An incomplete left homonymous hemianopia associated with a mild right optic neuropathy was found, and MRI showed a thickened, nodular, enhancing area in the paraclinoid and suprasellar regions with involvement of both optic nerves and the optic chiasm. Observation was elected, but the patient developed a severe headache with worsening visual loss over the next 6 weeks. Repeat MRI showed an increase in the extent of the area of the enhancing process (fig lA), and the patient was admitted to hospital.

At admission, visual acuity was $1 / 400$ temporally in the right eye and 20/40 in the left eye. Colour vision was markedly diminished in both eyes. Kinetic perimetry showed an incomplete, incongruous left homonymous hemianopia (fig 2A). There was no relative afferent pupillary defect. Extraocular motility was normal, as were corneal and facial sensation. The right optic disc was minimally pale; the left optic disc appeared normal. Lumbar puncture showed normal cerebrospinal fluid glucose and protein levels; there were 14 mononuclear white blood cells. Complete blood count and serum chemistries were normal. An acute infectious aetiology was determined to be unlikely, and the patient was treated with intravenous dexamethasone $10 \mathrm{mg}$ every 4 hours. Within 48 hours, visual acuity had improved to 20 200 in the right eye and 20/30 in the left eye, and the visual field of the right eye had expanded temporally. Intravenous dexamethasone was continued at $6 \mathrm{mg}$ every
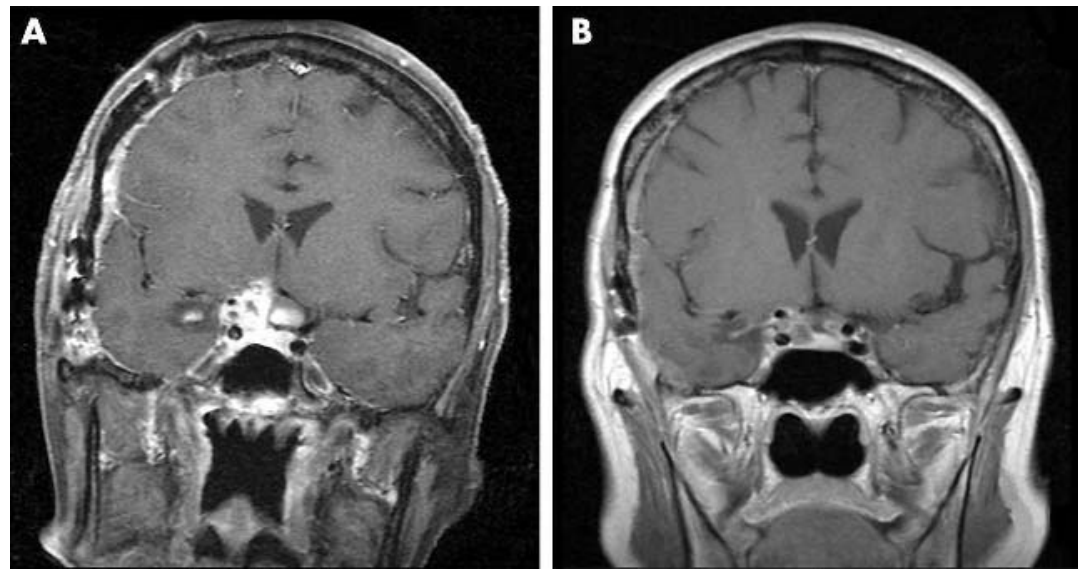

Figure $1 \mathrm{Tl}$ weighted coronal MRI of head with gadolinium contrast (A) obtained at the time of admission to hospital. An enhancing lesion surrounds the right internal carotid artery (ICA) and is adjacent to a smaller enhancing lesion abutting the left ICA. The process extends into the right temporal lobe. (B) 2 months after initiation of steroid therapy. Marked reduction in both the size and extent of the lesions as well as the degree of contrast enhancement is noted.
4 hours for 2 days, and then reduced to $4 \mathrm{mg}$ every 4 hours. After 7 days of treatment, the patient's visual acuity had improved to $20 / 40$ in the right eye and to $20 / 20$ in the left eye, with further expansion of the peripheral visual field of the right eye. Repeat MRI revealed marked reduction in the size and enhancement of the basal process.
The patient was discharged home on a 2 week tapering oral dose of dexamethasone.

Four weeks after discharge, the patient had visual acuity of 20/20 with slightly diminished colour vision in each eye. An incongruous, left homonymous hemianopia remained (fig $2 \mathrm{~B}-\mathrm{C}$ ), but as this visual field deficit was scotomatous rather than absolute,
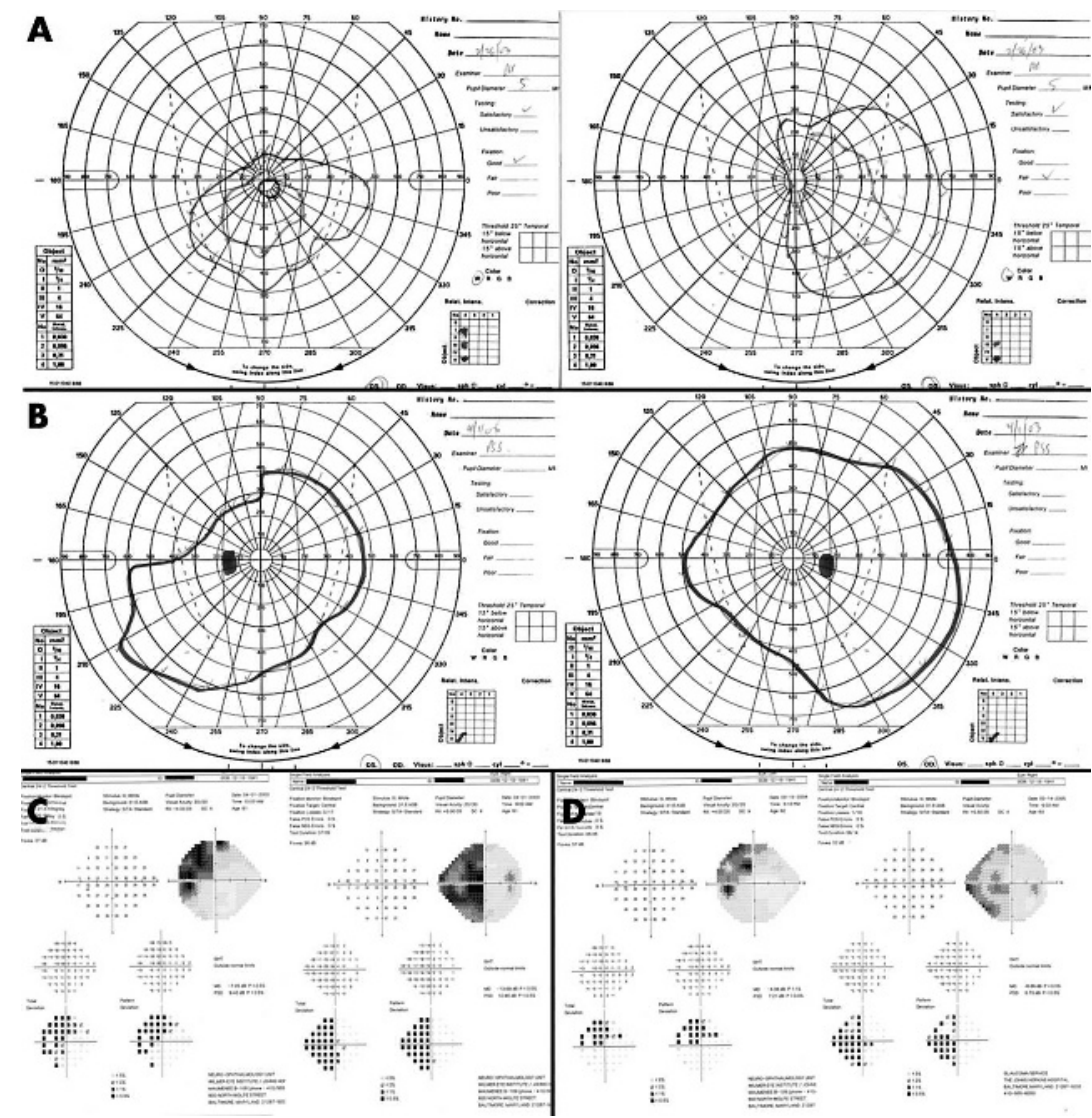

Figure 2 Kinetic perimetry with incongruous left homonymous hemianopia $(A)$ at the time of admission and (B) performed after 4 weeks of steroid therapy, with marked expansion of the peripheral visual field of each eye. Static perimetry results (Humphrey 24-2, SITA Standard), both eyes, demonstrate the scotomatous nature of the residual visual field defects (C) after 4 weeks of steroid therapy and (D) 2 years after steroid treatment for vision loss. 
the patient had been able to return to driving and was now able to perform all of the activities of daily living. MRI 6 weeks after discharge showed no evidence of enhancement or mass effect in the paraclinoid or suprasellar region (fig 1B). Two years after discharge and without further treatment, the patient remains well with stable vision and visual fields (fig 2D).

\section{Comment}

Reinforcement of unclippable intracranial aneurysms with autologous or alloplastic materials was proposed over 80 years ago, with subsequent studies showing that only a subset of these materials produce the desired local effect. ${ }^{1}$ Unfortunately, some patients in whom this treatment is used develop visual loss, occasionally several months or years after the surgery. ${ }^{6-9}$ Although both ischaemia and infection are thought to be inciting factors in some cases, ${ }^{10}$ most cases appear to result from an inflammatory reaction to the material used to wrap the aneurysm. ${ }^{67}$ The reason that the material incites such a reaction is unknown.

High quality MRI permits recognition of the inflammatory process that usually is found in cases of vision loss. ${ }^{3}$ Unlike in recent reports, ${ }^{2-4}{ }^{6}$ our patient presented with a markedly enhancing bilateral process that, after corticosteroid treatment, diminished greatly in both size and degree of contrast enhancement, providing an anatomical correlate with the functional improvement demonstrated clinically. In our patient, therapy was initiated approximately 2 months after the visual loss ensued, as was treatment in the other cases where no diminution of the inflammatory mass was seen. Thus, as noted by others, ${ }^{6}$ it seems clear that some patients recover spontaneously, some improve with steroid treatment, some improve with surgery, and some do not improve regardless of treatment.

To date, there has been no reported demonstration by MRI of size reduction of the inflammatory mass after medical therapy alone. We demonstrate here that cotton associated inflammation may respond dramatically to anti-inflammatory therapy both clinically and by neuroimaging. Furthermore, this case suggests that wrapping of intracranial aneurysms with cotton or cotton products reinforced with fibrin glue is justified when no suitable alternative exists, and that treatment with corticosteroids should be pursued aggressively should visual loss and imaging evidence of postoperative inflammation result, as non-surgical treatment may result in both anatomical and functional improvement. Should this treatment be unsuccessful, a neurosurgeon should be prepared to explore the patient and attempt debridement of the inflammatory process.

P S Subramanian, N R Miller Department of Ophthalmology, The Johns Hopkins Hospital, 600 N Wolfe Street, Baltimore, MD 21287 ,

V Renard, R J Tamargo, N R Miller Department of Neurosurgery, The Johns Hopkins Hospital, 600 N Wolfe Street, Baltimore, MD 21287

Correspondence to: Prem S Subramanian, MD, PhD, Ophthalmology Service, Walter Reed Army Medical Center, 6900 Georgia Ave NW, Washington DC 20307-5001, USA: prem.subramanian@na.amedd.army.mil doi: 10.1136/bjo.2005.078626

Accepted for publication 8 August 2005

Competing interets: none declared

\section{References}

1 Choudhari KA. Wrapping and coating of cerebral aneurysms: history, evolution and surgical management after a re-bleed. $\mathrm{Br} J$ Neurosurg 2004;18:259-67.

2 Berger C, Hartmann M, Wildemann B. Progressive visual loss due to a muslinomareport of a case and review of the literature. Eur J Neurol 2003;10:153-8.

3 Brochert A, Reynolds T, Baker R. MRI in a case of muslin-induced granuloma. Neuroradiology 2003;45:82-4.

4 Bhatti MT, Holder CA, Newman NJ, et al. MR characteristics of muslin-induced optic neuropathy: report of two cases and review of the literature. Am J Neuroradiol 2000;21:346-52.

5 McFadzean RM, Hadley DM, Mcllwaine GG. Optochiasmal arachnoiditis following muslin wrapping of ruptured anterior communicating artery aneurysms. J Neurosurg 1991;75:393-6.

6 Goldsberry DH, Ross IB, Dhillon G, et al. Visual dysfunction caused by gauze wrapping of an intracranial aneurysm. J Neuroophthalmol 2004;24:42-5.

7 Repka MX, Miller NR, Penix JO, et al. Optic neuropathy from the use of intracranial muslin. $J$ Clin Neuroophthalmol 1984;4:147-50.

8 Felsberg GJ, Tien RD, Haplea S, et al. Muslininduced optic arachnoiditis ("gauzoma"): findings on CT and MR. J Comput Assist Tomogr 1993;17:485-7.

9 Prabhu SS, Keogh AJ, Parekh HC, et al. Optochiasmal arachnoiditis induced by muslin wrapping of intracranial aneurysms. A report of two cases and a review of the literature. Br J Neurosurg 1994;8:471-6.

10 Kirollos RW, Tyagi AK, Marks PV, et al. Muslin induced granuloma following wrapping of intracranial aneurysms: the role of infection as an additional precipitating factor. Report of two cases and review of the literature. Acta Neurochir (Wien) 1997;139:411-15.

\section{MAILBOX}

\section{Visual loss may be due to silicone oil tamponade effect rather than silicone oil removal}

We read with great interest the article by Cazabon et al.

In all the three patients it would have been better to compare the visual acuity just before the silicone oil removal than immediate visual acuity after initial vitrectomy, because contact of the eye with the silicone oil could also be responsible for visual loss as it was known to cause optic nerve damage, as described in earlier reports. ${ }^{2}$

Earlier, Newsom et al also ${ }^{3}$ reported unexplained sudden visual loss following silicone oil removal in seven patients. They also observed only electrophysiological abnormalities.

Maybe the unexplained visual loss could be the result of optic nerve damage and diffuse gangilion cell dysfuntion caused by a silicone oil tamponade effect on the eye rather than the procedure of silicone oil removal itself.

P K Rani, R Raman, P Bhende, T Sharma Vitreoretinal Services, Sankara Nethralaya, 18 College Road, Chennai, 60006, India

Correspondence to: Dr Padmaja Kumari Rani, Vitreoretinal Services, Sankara Nethralaya, 18 College Road, Chennai, 60006, India; rpk11@yahoo.com doi: 10.1136/bjo.2005.082602

Accepted for publication 8 September 2005

\section{References}

1 Cazabon S, Groenewald C, Pearce IA, et al. Visual loss following removal of intraocular silicone oil. Br J Ophthalmol 2005;89:799-802.

2 Budde M, Cursiefen C, Holbach LM, et al. Silicone oil-associated optic nerve degeneration. Am J Ophthalmol 2001;131:392-4.

3 Newsom RS, Johnston R, Sullivan PM, et al. Sudden visual loss after removal of silicone oil. Retina 2004;24:871-7.

\section{Visual loss after silicone oil removal}

We read with interest the paper by Cazabon et $a l^{1}$ on the important emerging problem of sudden visual loss after removal of silicone oil. We have seen a similar pattern of visual loss in our own patients, typically in the macula on detachments associated with giant retinal tears. We have identified 12 cases in two units (St Thomas's, London, and Sunderland Eye Infirmary), but five of these clearly had onset of visual loss before oil removal (onset between 1 month and 5 months after oil insertion). ${ }^{2}$ Results of investigations were very similar to those reported by Cazabon et al. In four of five pattern ERG was suggestive of macular dysfunction. The timing of onset of visual loss obviously alters the potential aetiology, which as stated is unknown.

In their paper, information on acuity for cases 2 and 3, between 1 week after oil insertion and oil removal is not provided. Did these cases have visual loss preceding oil removal? Developing cataract can obviously hinder interpretation of acuity measurements. In our cases the symptoms described did not fit with cataract (scotoma, red desaturation) and persisted if any cataract was removed.

We have seen a further case since this report, a 46 year old woman with a giant retinal tear and macula-on retinal detachment affecting the right eye. Acuity reduced during the period of tamponade from 6/6 at 2 weeks after oil insertion to $6 / 36+1$, which did not recover after oil removal. She reported a central negative scotoma. Electrophysiology suggested macular dysfunction.

We have speculated that phototoxicity may have a role, as oil transmits light more in the blue spectrum than aqueous. ${ }^{3}$ The fat soluble macular pigments, lutein and zeaxanthin, are thought to protect the macula from photooxidative damage. Silicone oil has previously been reported to dissolve fat soluble elements from the retina. ${ }^{4}$

We measured the macular pigment optical density (MPOD) in this case using a modified confocal scanning laser ophthalmoscope and two wavelength autofluorescence technique 3 weeks after oil removal. The results showed a substantially reduced MPOD in the eye that had silicone oil compared to the fellow eye. Although the peak MPOD, at the foveal centre of both eyes was similar ( 0.47 right versus $0.52 \mathrm{left})$, the MPOD at $1 / 2$ degree, 1 degree, and 2 degrees eccentricity from the foveal centre was markedly lower in the eye that had silicone oil $(0.12,0.06,0.02$ respectively versus $0.40,0.22,0.07)$.

Although MPOD varies greatly between individuals, there is usually high interocular symmetry in normal eyes. ${ }^{5}$ Further work is required to determine whether or not this relates to the visual loss and whether 
therapeutic supplementation may reduce the risk of visual loss.

E N Herbert, S H M Liew, T H Williamson Department of Ophthalmology, St Thomas's Hospital, Lambeth Palace Road, London SEI 7EH, UK

Correspondence to: Mr Edward N Herbert Department of Ophthalmology, St Thomas's Hospital, Lambeth Palace Road, London SE1 7EH, UK enherbert@doctors.org.uk

doi: 10.1136/bjo.2005.082610

\section{References}

Accepted for publication 8 September 2005

1 Cazabon S, Groenewald C, Pearce IA, et al. Visual loss following removal of intraocular silicone oil. Br J Ophthalmol 2005;89:799-802.

2 Herbert EN, Habib M, Steel D, et al. Central scotoma associated with intraocular silicone oil tamponade develops before oil removal. Graefes Arch Clin Exp Ophthalmol DOI 10.1007/ s00417-005-0076-6.

3 Azzolini C, Docchio F, Brancato R, et al. Interactions between light and vitreous fluid substitutes. Arch Ophthalmol

1992;110:1468-71.

4 Refojo MF, Leong FL, Chung $\mathrm{H}$, et al. Extraction of retinol and cholesterol by intraocular silicone oils. Ophthalmology 1998:95:614-18.

5 Bone RA, Sparrock JM. Comparison of macular pigment densities in human eyes. Vis Res 1971;11:1057-64.

\section{Visual loss following silicone oil removal}

We congratulate Cazabon et al on their recent, well illustrated, report. ${ }^{1}$ Their cases reflect a similar group of seven patients we recently observed at Moorfields Eye Hospital. ${ }^{2}$ They were relatively young, 19-57 years old, had macula-on, or "just off" retinal detachments. Five of seven had giant retinal tears and the others multiple posterior tears with retinal detachment. Following vitrectomy and oil insertion, vision was good and then fell when the silicone oil was removed. The oil was in place for between 105-220 days; three patients had combined cataract surgery with oil removal.

One difference between the reports is that vision in our group fell immediately following oil removal, whereas in Liverpool patients reported visual loss at 1 week. Visual loss could be severe, some lost vision to counting fingers with a relative afferent papillary defect, and all lost vision without macular signs, optical coherence tomographic, or angiographic changes.

The interpretation of electrophysiological changes is different from that in our paper, where macular dysfunction was associated with generalised retinal dysfunction in some patients and with an optic neuropathy in one. In this paper only the macular function is commented on, the $30 \mathrm{~Hz}$ cone flicker being presented, and it is therefore difficult to compare data without the full ISCEV data. ${ }^{34}$ It is not clear how the pattern visually evoked potential (VEP) can be "normal" in case 1, with a visual acuity of 6/36 and an abnormal pattern electroretinogram (PERG); even in macular disease with this level of visual acuity and an abnormal PERG, the pattern VEP is invariably abnormal.

A recent report of optic neuropathy induced by silicone oil may perhaps explain our findings in one case. ${ }^{5}$ However, all the other cases reported so far seem to point to a new as yet unexplained phenomenon of sudden visual loss following silicone oil removal. Photoreceptor apoptosis, triggered by rapid change in vitreous potassium concentrations, is an attractive theory, but more work is required to elucidate this phenomenon further. In the meantime we advocate a cautious approach to silicone oil in patients with macular-on detachments.

R S B Newsom, R Johnston, P Sullivan, B Aylward, G Holder, Z Gregor Southampton Eye Unit, UK

Correspondence to: Richard S B Newsom, Southampton Eye Unit, UK richard.newsom@shut.nhs.uk

doi: 10.1136/bjo.2005.082644

Accepted for publication 8 September 2005

\section{References}

1 Cazabon S, Groenewald C, Pearce IA, et al Visual loss following removal of intraocular silicone oil. Br J Ophthalmol 2005;89:799-802.

2 Newsom RS, Johnston R, Sullivan PM, et al. Sudden visual loss after removal of silicone oil. Retina 2004;24:871-7.

3 Fishman GA, Birch DG, Holder GE, et al. Electrophysiologic testing in disorders of the retina, optic nerve, and visual pathway. 2 nd ed. Ophthalmology monograph 2. San Francisco: The Foundation of the American Academy of Ophthalmology, 2001

4 Marmor MF, Hood DC, Keating D, et al. Guidelines for basic multifocal electroretinography (mfERG). Doc Ophthalmol 2003; 106:105-15.

5 Eckle D, Kampik A, Hintschich C, et al. Visual field defect in association with chiasmal migration of intraocular silicone oil. Br J Ophthalmol 2005;89:918-20.

\section{CORRECTION}

doi: 10.1136/bjo.2005.63123corr 1

The paper titled, Intermittent extropia increasing with near fixation: a "soft" sign of neurological disease $(\mathrm{Br} J$ Ophthalmol 2005:89;1120-2) has been reprinted in this issue due to an error in the final paragraph, which has now been corrected.

\section{NOTICES}

\section{World Ophthalmology Congress 2006 - Brazil}

The World Ophthalmology Congress (which is replacing the International Congress of Ophthalmology) is meeting in February 2006 in Brazil.

For further information on the congress and committees, scientific program and coordinators of different areas are available at the congress website www.ophthalmology2006. com.br

\section{Vision 2020}

The latest issue of Community Eye Health (No 54) assesses the progress of Vision 2020 at the district level. For further information please contact: Journal of Community Eye Health, International Resource Centre, International Centre for Eye Health, Department of Infectious and Tropical Diseases, London School of Hygiene and Tropical Medicine, Keppel Street, London WClE 7HT, UK (tel: +44 (0)20 7612 7964; email: Anita.Shah@lshtm.ac.uk; online edition: www.jceh.co.uk). Annual subscription ( 4 issues) UK $£ 28 /$ US $\$ 45$. Free to developing country applicants.

\section{$19^{\text {th }}$ International Society for Geographical \& Epidemiological Ophthalmology Congress}

The $19^{\text {th }}$ ISGEO congress will be held in Sao Paulo, Brazil on 18-19 February, 2006, just prior to the ICO. Abstract submission and registration forms can be obtained by emailing Dr Paul Courtright (pcourtright@kcco. net, url: ) or by accessing the ISGEO website at www.kcco.net/isgeo.

\section{Medical Contact Lens \& Ocular surface Association Winter Symposium}

The MCLOSA Winter Symposium will be held at the Western Eye Hospital, Marylebone Road, London NWl on Friday 18 November 2005. For further information please visit the MCLOSA website at www.mclosa.org.uk/ annualmtg.html. 


\section{SCIENTIFIC REPORT}

\section{Intermittent exotropia increasing with near fixation: a "soft" sign of neurological disease P H Phillips, K J Fray, M C Brodsky}

\begin{abstract}
Aim: To examine the association of distance-near disparity with neurological disease in children with intermittent exotropia. Methods: A retrospective analysis was performed of the medical records of all children with intermittent exotropia examined at the Arkansas Children's Hospital between 1989 and 2002. The study group consisted of children with intermittent exotropia who had a near deviation that exceeded the deviation at distance by at least 10 prism dioptres. The control group consisted of children with intermittent exotropia who had a distance deviation greater than or equal to the deviation at near. The main outcome measures were the prevalence of neurological abnormalities in the study and control groups.

Results: Among the 29 patients in the study group, 19 (66\%) had a history of concurrent neurological abnormalities. Associated neurological conditions included developmental delay (10 patients), attention deficit disorder (four patients), cerebral palsy (four patients), history of intracranial haemorrhage (four patients), periventricular leucomalacia (three patients), seizures (two patients), cortical visual impairment (two patients), hydrocephalus (one patient), history of anoxic brain damage (one patient), history of encephalitis (one patient), and autism (one patient). Among the 37 patients in the control group, seven (19\%) had a history of concurrent neurological abnormalities. The difference in the prevalence of neurological disease between the study group and the control group was significant $(p=0.0002)$.

Conclusion: Intermittent exotropia increasing with near fixation is associated with neurological disease in children.
\end{abstract}

C hildren with intermittent exotropia often have an exodeviation that increases with distance fixation. ${ }^{12}$

However, some children exhibit an exodeviation that increases during near fixation. It has been our impression that the latter group frequently has associated neurological or neurodevelopmental disorders. To test this hypothesis, we retrospectively reviewed the medical records of our patients with intermittent exotropia.

\section{METHODS}

Retrospective analysis of the medical records of all children with intermittent exotropia examined at the Arkansas Children's Hospital between 1989 and 2002. The study group consisted of children with intermittent exotropia whose near deviation was at least 10 prism dioptres greater than their distance deviation. The control group consisted of children with intermittent exotropia who had a distance deviation greater than or equal to the deviation at near. Children who had strabismus surgery were categorised by ocular motility measurements obtained before their strabismus surgery. Children who had undergone strabismus surgery before examination by one of the investigators were excluded from the analysis. In addition, children who had a near deviation that was less than 10 prism dioptres greater than the distance deviation, who had an inconsistent distance/near disparity, or who were uncooperative for distance and near measurements were excluded from the analysis. None of the patients had amblyopia, ptosis, anisocoria, nystagmus, limited ductions or any other associated ocular disease. The absence of amblyopia was confirmed in preverbal children by the ability to maintain central steady fixation with each eye and among literate children, by the presence of visual acuity equal to or greater than 20/30 in each eye and equal visual acuity in both eyes.

All patients were examined by at least two investigators. Cover/uncover testing was used to diagnosis intermittent exotropia. Prism and alternate cover testing was performed with distance $(6$ metres) and near $(33 \mathrm{~cm})$ fixation targets in order to determine the magnitude of the exodeviation. Accurate fixation and accommodation were assured by having the patient identify different fixation targets as measurements were being obtained. Depending on the age and development of the patient, Snellen letters or Allen symbols were used as fixation targets. Ocular occlusion was not performed before obtaining the measurements noted above. When possible, confrontation visual field testing was performed to rule out hemianopic visual field deficits.

The charts were reviewed for the presence of associated ocular, neurological and systemic diseases. All patients and parents in the study and control groups were routinely questioned at each visit regarding the presence of neurological diseases including developmental delay, attention deficit disorder, and seizures. Most of the patients diagnosed with neurological disease were evaluated by a paediatric neurologist or a child development specialist before their ophthalmologic evaluation.

\section{Statistical analysis}

The prevalence of neurological disease and the sex distribution in the study and control groups were compared with a two tailed $\chi^{2}$ test. The age distribution in each group was compared with a two sample $t$ test.

\section{RESULTS}

A total of 94 children had intermittent exotropia. Twenty eight children were excluded from the analysis. Reasons for exclusion included insufficient cooperation for accurate distance measurements (18 patients), an exodeviation at near that exceeded the deviation at distance by less than 10 prism dioptres (eight patients), strabismus surgery that 
Table 1 Characteristics of the study and control groups

\begin{tabular}{lllll}
\hline & $\begin{array}{l}\text { Sex (no of females) } \\
\text { (mean) }\end{array}$ & $\begin{array}{l}\text { Age (years) } \\
\text { (mean (SD)) }\end{array}$ & $\begin{array}{l}\text { Distance deviation } \\
\text { (prism dioptres) } \\
\text { (mean (SD)) }\end{array}$ & $\begin{array}{l}\text { Near deviation } \\
\text { (prism dioptres) }\end{array}$ \\
\hline Study group $(\mathrm{n}=29)$ & 13 & $\begin{array}{l}6.7(8.3) \\
\text { range 3-17 }\end{array}$ & $\begin{array}{l}19(10) \\
\text { range 0-40 }\end{array}$ & $\begin{array}{l}35(11) \\
\text { range 10-55 }\end{array}$ \\
$\begin{array}{l}\text { Control group } \\
(\mathrm{n}=37)\end{array}$ & 17 & $\begin{array}{l}4.4(9.0) \\
\text { range 3-14 }\end{array}$ & $\begin{array}{l}30(11) \\
\text { range 14-60 }\end{array}$ & $\begin{array}{l}13(11) \\
\text { range 0-45 }\end{array}$ \\
$\mathrm{p}$ Value & 0.87 & 0.24 & & \\
\hline
\end{tabular}

was performed before evaluation by one of the investigators (one patient), and ocular motility measurements that were inconsistent (one patient).

The characteristics of the study and control groups are shown in table 1 . The study and control groups did not differ significantly with respect to sex and age at evaluation. The 29 patients in the study group had intermittent exotropia that increased with near fixation with a mean deviation of 19 prism dioptres at distance and 35 prism dioptres at near. Seventeen of these 29 patients had an intermittent near deviation greater than or equal to 35 prism dioptres indicating robust fusional convergence amplitudes; 19 of these 29 patients $(66 \%)$ had a history of concurrent neurological abnormalities as listed in table 2 .

The control group consisted of 37 patients with a mean exodeviation of 30 prism dioptres at distance and 13 prism dioptres at near. Seven of these 37 patients (19\%) had a history of concurrent neurological abnormalities as listed in table 2. The prevalence of neurological abnormalities was significantly higher in the patients who had an intermittent exotropia that increased with near fixation compared with the control group $(p=0.0002)$. Despite the significant difference in prevalence, the spectrum of neurological abnormalities was qualitatively similar between both groups.

\section{DISCUSSION}

We found a high prevalence of neurological disease in children with intermittent exotropia increasing at near fixation. Exodeviations that increase during near fixation have been associated with several neurological disorders including head trauma, dyslexia, Parkinson's disease, congenital central hypoventilation syndrome, subdural haematoma, and stroke. ${ }^{3-14}$ The term "convergence insufficiency" has been loosely applied to this heterogeneous group of patients with exodeviations that become problematic during near fixation. In this context, apparent convergence insufficiency may arise from multiple mechanisms ranging from decreased fusional convergence amplitudes, a low accommodative convergence/accommodation ratio, accommodative insufficiency, poor convergence effort, poor accommodative effort, poor concentration, and pharmacological effects of medications. ${ }^{3-14}$ We are unable to assign a specific neurophysiological substrate to our study patients with intermittent exotropia that increases with near fixation. However, many of our study patients were able intermittently to fuse large exodeviations, demonstrating that their convergence amplitudes were greater than normal.

The magnitude of exodeviations at near is affected by accommodative and convergence effort. We encouraged accommodative and convergence effort by requiring our children to identify fixation targets as measurements were being obtained. However, we cannot exclude the possibility that reduced accommodative or convergence effort may have contributed to the high prevalence of exodeviations that increase with near fixation in children with neurological disease.

This study should be viewed in light of its inherent limitations. Firstly, because our cohort was gleaned from a children's hospital population, our findings do not necessarily reflect the prevalence of neurological dysfunction in the general population. However, the increased prevalence of neurological disease in our children with intermittent exotropia that increases with near fixation compared with our control group of patients suggests that this association is real. Secondly, the prevalence of neurological disease was determined from a retrospective chart review. Not every patient was examined by a paediatric neurologist. However, patients and parents were routinely questioned regarding the presence of neurological disease at each visit. It is unlikely that a more detailed paediatric neurological evaluation would have disclosed clinically significant undiagnosed neurological disease in a significant number of our apparently healthy patients. Finally, we did not formally measure accommodative

Table 2 Neurological diseases in study and control patients

\begin{tabular}{llll}
\hline & Study group $(\mathbf{n}=29)$ & & Control group $(\mathbf{n}=\mathbf{3 7})$ \\
\cline { 2 - 2 } Neurological diseases & No of patients* & & No of patients* \\
\hline Developmental delay & 10 & 2 \\
Cerebral palsy & 4 & 1 \\
Attention deficit disorder & 4 & 0 \\
History of intracranial haemorrhage & 4 & 1 \\
Periventricular leucomalacia & 3 & 4 \\
Seizure disorder & 2 & 0 \\
Cortical visual impairment & 2 & 0 \\
History of hydrocephalus & 1 & 0 \\
History of anoxic brain damage & 1 & 1 \\
History of encephalitis & 1 & \\
Autism & 1 & \\
\hline *Most patients had more than one neurological abnormality &
\end{tabular}


or convergence amplitudes in most of our patients with intermittent exotropia that increases with near fixation.

Our study confirms a high prevalence of neurological disease in children who have intermittent exotropia that increases with near fixation. However, no patient was subsequently found to have a serious treatable neurological lesion. As such, neuroimaging is not warranted, and further diagnostic evaluation can be guided by the clinical history. Although the determinants of increased near disparity in intermittent exotropia have yet to be defined, this form of strabismus appears to be a "soft" sign of neurological disease in children.

\section{ACKNOWLEDGEMENT}

Supported in part by unrestricted grant from Research to Prevent Blindness and the Pat \& Willard Walker Eye Research Center, Jones Eye Institute, University of Arkansas for Medical Sciences.

\section{Authors' affiliations \\ P H Phillips, K J Fray, M C Brodsky, Department of Ophthalmology, University of Arkansas for Medical Sciences, Little Rock, AR, USA M C Brodsky, Department of Pediatrics, University of Arkansas for Medical Sciences, Little Rock, AR, USA}

Correspondence to: Paul H Phillips, MD, Arkansas Children's Hospital, 800 Marshall Street, Little Rock, AR 72202, USA; phillipspaulh@uams.edu

Accepted for publication 1 March 2005

\section{REFERENCES}

1 Kushner BJ, Morton GV. Distance/near differences in intermittent exotropia. Arch Ophthalmol 1998; 116:478-86.

2 Kushner BJ. Exotropic deviations: a functional classification and approach to treatment. Am Orthopt J 1998;38:81-93.

3 Krohel GB, Kristan RW, Simon JW, et al. Posttraumatic convergence insufficiency. Ann Ophthalmol 1986;18:101-4.

4 Lepore FE. Disorders of ocular motility following head trauma. Arch Neurol 1995; 52:924-6.

5 Cohen M, Groswasser Z, Barchadski R, et al. Convergence insufficiency in brain-injured patients. Brain Injury 1989;3:187-91.

6 Kowal L. Ophthalmic manifestations of head injury. Aust N Z J Ophthalmol 1992;20:35-40.

7 Al-Qurainy IA. Convergence insufficiency and failure of accommodation following midfacial trauma. Br J Oral Maxillofac Surg 1995;32:71-5.

8 Latvala $M-L$, Korhonen $\Pi$, Penttinen $M$, et al. Ophthalmic findings in dyslexic school children. Br J Ophthalmol 1994;78:339-43.

9 Racette BA, Gokden M, Tychsen L, et al. Convergence insufficiency in idiopathic Parkinson's disease responsive to levodopa. Strabismus 1999;7:169-74.

10 Repka MX, Claro MC, Loupe DN, et al. Ocular motility in Parkinson's disease. J Pediatr Ophthalmol Strabismus 1996;33:144-7.

11 Goldberg DS, Ludwig IH. Congenital central hypoventilation syndrome: Ocular findings in 37 children. J Pediatr Ophthalmol Strabismus 1996;33:175-80.

12 Spierer A, Huna R, Rechtman C, et al. Convergence insufficiency secondary to subdural hematoma. Am J Ophthalmol 1995;120:258-60.

13 Ohtsuka K, Maekawa H, Takeda M, et al. Accommodation and convergence insufficiency with left middle cerebral artery occlusion. Am J Ophthalmol 1988; 106:60-4.

14 Stavis M, Murray M, Jenkins $P$, et al. Objective improvement from base-in prisms for reading discomfort associated with mini-convergence insufficiency type exophoria in school children. Binoc Vis Strabismus Q 2002;17:135-42. 